\title{
Carbon-Based Materials in Photodynamic and Photothermal Therapies Applied to Tumor Destruction
}

\author{
Karina J. Lagos ${ }^{1}$, Hilde H. Buzzá ${ }^{2,3}{ }^{\mathbb{D}}$, Vanderlei S. Bagnato $\left.{ }^{3}{ }^{(}\right)$and María Paulina Romero ${ }^{1, *}$ \\ 1 Department of Materials, Escuela Politécnica Nacional (EPN), Quito 170525, Ecuador; \\ karina.lagos@epn.edu.ec \\ 2 Institute of Physics, Pontificia Universidad Católica de Chile, Santiago 7820436, Chile; hilde.buzza@fis.uc.cl \\ 3 São Carlos Institute of Physics, University of São Paulo (USP), São Carlos 13566-590, Brazil; \\ vander@ifsc.usp.br \\ * Correspondence: maria.romerom@epn.edu.ec
}

Citation: Lagos, K.J.; Buzzá, H.H.; Bagnato, V.S.; Romero, M.P. Carbon-Based Materials in Photodynamic and Photothermal Therapies Applied to Tumor Destruction. Int. J. Mol. Sci. 2022, 23, 22. https://doi.org/10.3390/ ijms23010022

Academic Editor: Bertrand Liagre

Received: 30 October 2021

Accepted: 27 November 2021

Published: 21 December 2021

Publisher's Note: MDPI stays neutral with regard to jurisdictional claims in published maps and institutional affiliations.

Copyright: (C) 2021 by the authors. Licensee MDPI, Basel, Switzerland. This article is an open access article distributed under the terms and conditions of the Creative Commons Attribution (CC BY) license (https:// creativecommons.org/licenses/by/ $4.0 /)$.

\begin{abstract}
Within phototherapy, a grand challenge in clinical cancer treatments is to develop a simple, cost-effective, and biocompatible approach to treat this disease using ultra-low doses of light. Carbonbased materials (CBM), such as graphene oxide (GO), reduced GO (r-GO), graphene quantum dots (GQDs), and carbon dots (C-DOTs), are rapidly emerging as a new class of therapeutic materials against cancer. This review summarizes the progress made in recent years regarding the applications of CBM in photodynamic (PDT) and photothermal (PTT) therapies for tumor destruction. The current understanding of the performance of modified CBM, hybrids and composites, is also addressed. This approach seeks to achieve an enhanced antitumor action by improving and modulating the properties of CBM to treat various types of cancer. Metal oxides, organic molecules, biopolymers, therapeutic drugs, among others, have been combined with CBM to treat cancer by PDT, PTT, or synergistic therapies.
\end{abstract}

Keywords: phototherapy; cancer; graphene oxide; reduced graphene oxide; graphene quantum dots; carbon dots

\section{Introduction}

Phototherapy is a non-traditional strategy that has been used within several bioapplications. For example, in antimicrobial treatments, light stimulation of an agent promotes the inactivation of bacteria, protozoa, viruses, and fungi [1-3]. Likewise, various diseases such as vitiligo [4], psoriasis [5], atopic dermatitis [6], cancer [7], and so on, have been diagnosed and treated by this approach.

Cancer has become a disease of significant concern in recent years due to its threat to human life, causing millions of deaths. The International Agency for Research on Cancer reported 9.9 million worldwide diseases in 2020 (world ASR of 100.7) [8]. Thus, several studies have proposed phototherapy using nanomaterials as photoabsorbing agents as an alternative to treat cancer [9-11]. It is worth noting that phototherapy is advantageous compared to radiotherapy, chemotherapy, or surgery owing to its simple operation, minimally invasive procedure, reduced toxicity, minor trauma, fewer adverse reactions, and negligible drug resistance [12,13]. Nevertheless, it has drawbacks as poor penetration limits its action in optically inaccessible deep tumors. To overcome these weaknesses, novel flexible light sources and devices have been designed, and approaches such as X-ray radiation, NIR light, and internal self-luminescence have been proposed [14].

Photodynamic therapy (PDT) and photothermal therapy (PTT) are encompassed within phototherapy. When light of a suitable wavelength is irradiated upon a defined molecule photosensitizer (PS) or photothermal agent (PA), reactive oxygen species (ROS) and heat are generated, respectively, in PDT and PTT, which causes damage to malignant cells in cancer $[15,16]$. In PDT, the PS is excited by light. In this state, the PS reacts with nearby molecular oxygen and generates ROS, either type I (free radicals) or type II (singlet 
oxygen, ${ }^{1} \mathrm{O}_{2}$ ) reactions. In cancer treatments, this action results in apoptosis, necrosis, or autophagy of the abnormal cells inhibiting the tumor growth [17]. The efficiency of PDT is related to the ROS generation yield, which depends on the PS, dose, source light, and tissue oxygen [18]. PTT is based on localized hyperthermia. The PAs are irradiated by light and they absorb photons which produces an excited state. By non-radiative relaxation pathways, heat is generated to dissipate this excess of energy [19]. When the temperature of the PAs surrounding the environment rises, cancerous cells are destroyed due to their low heat tolerance compared to normal cells. Thus, the targeting capability of PSs and PAs in tumor cells is key to concentrating their action in cancer tissue [20,21].

In both therapies, PDT and PTT, particular properties in their active agents are required, as well as robust responses to light stimuli. Furthermore, high specificity, biocompatibility, low dark toxicity, and optical characteristics are desirable [22]. On this basis, carbon-based materials (CBM) have become excellent candidates as phototherapy agents and as platforms or carriers of these compounds [17,23-25]. The specificity of CBM accomplishes focusing its action only on cancerous cells. These materials are critical components due to their remarkable advantages, such as reduced side effects and low toxicity in specific concentrations $[17,26]$. Phototherapy agents can also be loaded with drugs or combined with other materials to enhance their antitumoral action or to improve and modulate their properties, making possible the effective application of distinct mechanisms of action [27]. Thus, the doping and hybrid behavior of CBM along with synergistic therapies are also addressed in this review.

\section{Carbon-Based Materials (CBM) Applied in Photodynamic (PDT) and Photothermal (PTT) Therapies}

CBM have been considered a phototherapy agent due to their remarkable features. Nevertheless, it is worth noting that the properties of any CBM vary according to their specific structure (size and shape), which is determined by the method of synthesis, along with their experimental conditions and carbon source nature. Concerning the latter, some authors have even proposed using residues such as bio-mass and polymers waste [28,29]. To synthesize CBM, two approaches have been employed; (i) top-down: reduction of size from bulk materials, such as mechanical or chemical exfoliation, and (ii) bottom-up: construction from the atomic level, like epitaxial growth and chemical vapor deposition [30,31].

Within CBM, graphene has become one of the most studied materials owing to its unique chemical and physical properties [32,33] which have encouraged its application in diverse fields such as electronics, material science, energy, and biomedicine, including the treatment of the COVID-19 disease [34-37]. Regarding bio-applications, the versatility of graphene has allowed its assessment as an antimicrobial agent [38], in sensors [39], drug delivery [40], bioimaging [41], regenerative medicine [42], cancer treatment [43,44], and photodynamic and photothermal therapies $[45,46]$. However, the hydrophobicity of the pristine graphene has turned into a drawback when affinity with physiological solutions or water is desirable [47]. Moreover, graphene tends to agglomerate in solution and has poor solubility. In this context, some alternatives have been proposed to overcome this limitation. For example, functionalized graphene derivatives such as graphene oxide (GO), reduced graphene oxide (r-GO), or graphene quantum dots (GQDs) have been employed instead (see Figure 1). These derivatives have excelled as novel materials due to their large specific surface area, bio-compatibility, solubility, and selectivity $[48,49]$. 


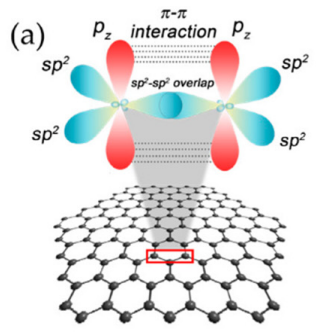

Graphene

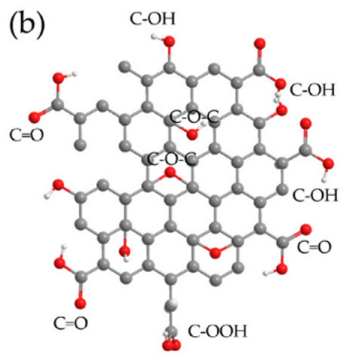

Graphene oxide

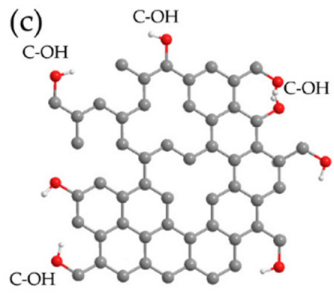

Reduced graphene oxide (d)

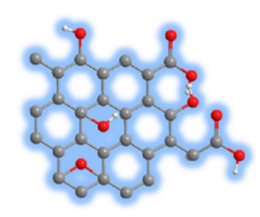
Graphene-based quantum dot

Figure 1. CBM: (a) Graphene with $\mathrm{sp}^{2}$-hybridized carbon atoms; (b) GO; (c) r-GO and (d) GQD. Reproduced from Ref. [50]. Copyright 2017 MDPI.

Another enthralling new material with comparable properties to those of graphene derivatives is carbon dots (C-DOTs). These OD materials with sizes below $10 \mathrm{~nm}$ and an easy ability to be synthesized have also been extensively used in bio-applications [51-53].

In this section, GO, r-GO, GQDs, C-DOTs, and their composites and hybrids are addressed as new materials in phototherapy and synergistic therapies against cancer disease.

\subsection{Graphene Oxide (GO)}

GO has a 2-dimensional (2D) honeycomb structure with $\mathrm{sp}^{3}$ domains enclosing $\mathrm{sp}^{2}$ carbon domains and is covalently functionalized with carbon and oxygen groups [54]. These attachments differentiate GO from graphene. The presence of carboxylic (-COOH), hydroxyl $(-\mathrm{OH})$, carbonyl $(\mathrm{C}=\mathrm{O})$, alkoxy $(\mathrm{C}-\mathrm{O}-\mathrm{C})$, epoxy $(>\mathrm{O})$, or other functional groups induces changes in specific GO properties such as its characteristic insulator behavior and water affinity $[55,56]$. The functionalizations allow the establishment of covalent bonds with other species. Figure 2 presents some materials that have been employed to modify GO's surface.

Some studies have reported sulfur contents in GO, which also induces substantial variations in its acidic and electric properties [57]. It is worth indicating that these couplings trigger an expansion in the interlayer spacing, doubling the GO size compared to graphene. Generally speaking, the properties of GO consist of the planar layer structure, high thermal and electrical conductivity, excellent optical transmittance, and flexibility of surface modification [58].

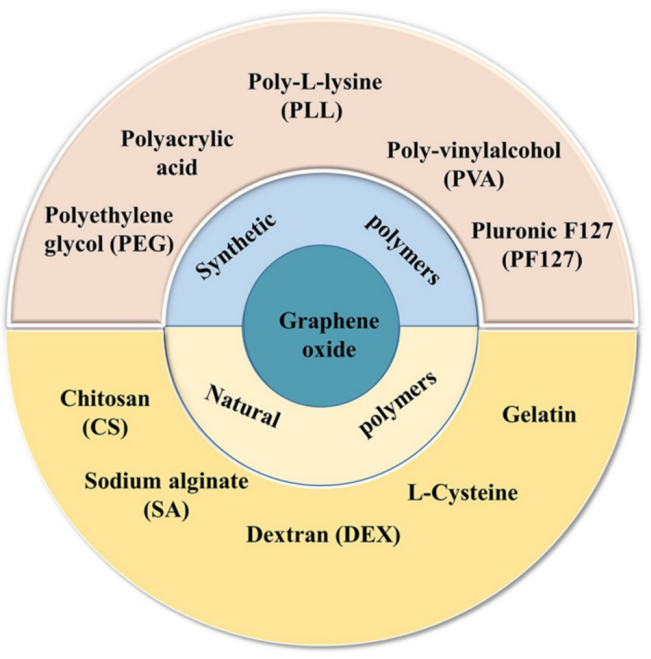

Figure 2. Materials used for the surface modification of GO. Reproduced from Ref. [59]. Copyright 2021 Springer Nature. 


\subsubsection{Application of GO in PDT}

Several studies have employed GO and standard photosensitizers (PSs) for cancer treatment. Hosseinzadeh R. et al. (2018) fabricated a PS using GO and methylene blue. The potential of the PS for killing cancer cells was evaluated by the Thiazolyl Blue (MTT) cell viability assay employing a human breast cancer cell line (MDA-MB-231). Using a concentration of $20 \mu \mathrm{g} / \mathrm{mL}$ in dark conditions, the results of cell viability showed a reduction of up to $60 \%$ for the PS, having a much better performance than the components separately, which did not present a significant decrease, barely less than $5 \%$. In contrast, under irradiation with red LED illumination of $630 \mathrm{~nm}$ for $30 \mathrm{~min}$, a reduction of up to $80 \%$ was obtained employing the same concentration of the PS [60]. Likewise, Sun X. et al. (2018) developed a GO-based nanocomposite. For this, they encapsulated TPE-red (tetraphenylethyleneaggregation-induced emission nanoparticles) with modified GO by PEGylation procedure. They demonstrated that the nanocomposite increased the production of ROS under laser irradiation of $450 \mathrm{~nm}$, enhancing the ROS generation capability compared to single TPEred. Besides, an MTT assay was carried out on UMUC3 cells indicating higher toxicity under radiation than in dark conditions [61]. Qin et al. (2018) fabricated a nanocomposite with $\mathrm{GO}$, magnetic nanoparticles $\left(\mathrm{Fe}_{3} \mathrm{O}_{4}\right)$, chitosan, and a novel photosensitizer $\mathrm{HNPa}$ (3-[1-hydroxyethyl]-3-divinyl-131-b,b-dicyano-methylene-131-deoxopyropheophorbide-a). They confirmed a superior singlet oxygen quantum yield compared to the single $\mathrm{HNPa}$, being $62.9 \%$ and $42.6 \%$, respectively. Furthermore, they demonstrated that the presence of $\mathrm{GO}-\mathrm{Fe}_{3} \mathrm{O}_{4}$ accelerated the penetration of HNPa into the nucleus of the human hepatocellular carcinoma cell line (HepG-2). Besides this, an MTT assay carried out under $698 \mathrm{~nm}$ of irradiation verified an enhanced result of HNPa to increase photodynamic cancer cell death [62].

A simplified scheme of GO-composite application in PDT is shown in Figure 3.

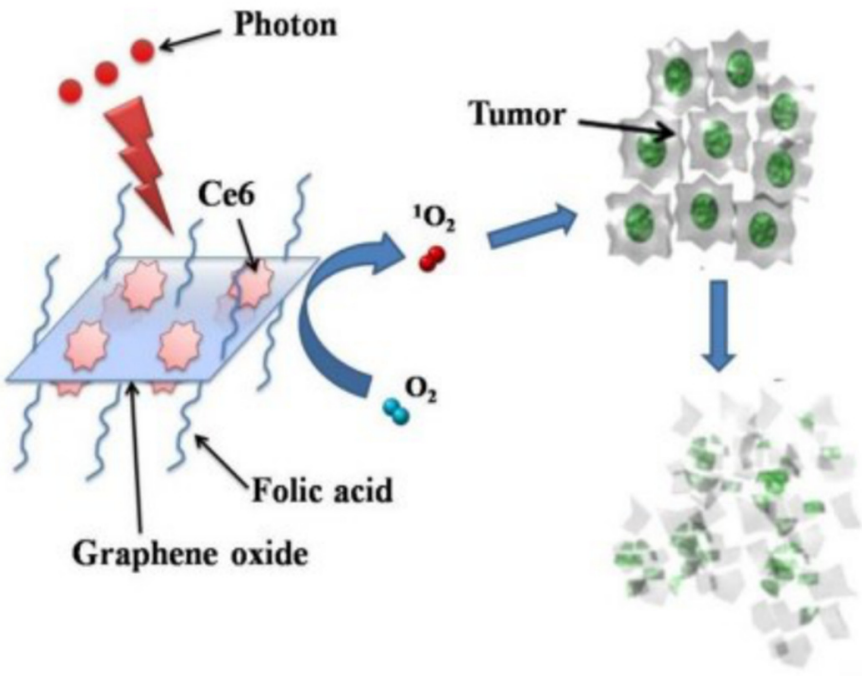

Figure 3. PS molecules of Chlorin e6 (Ce6) loaded by folic acid-conjugated GO for PDT applications in cells. Reproduced from Ref. [63]. Copyright 2012 PubMed Central.

\subsubsection{Application of GO in PTT}

The excellent efficiency of GO photothermal conversion in the NIR region makes it susceptible to use in PTT [64]. In recent years, highly elaborate hybrids have been developed to improve the solubility and selectivity of GO. Lim et al. (2018) fabricated a $\sim 155 \mathrm{~nm}$ nanocomposite using GO along folic acid and manganese dioxide $\left(\mathrm{MnO}_{2}\right)$. In cancer, the $\mathrm{MnO}_{2}$ decomposes hydrogen peroxide into oxygen, relieving hypoxia. The results show that the composite heat capacity was better than a single GO. Under $808 \mathrm{~nm}$ laser excitation of $3.5 \mathrm{~min}$, the nanocomposite reaches the desired temperature of $47^{\circ} \mathrm{C}$ while GO reaches barely $35^{\circ} \mathrm{C}$ [65]. 
Similarly, Xie et al. (2019) fabricated a composite with good stability and dispersibility from $\mathrm{GO}$, magnetic nanoparticles $\left(\mathrm{Fe}_{3} \mathrm{O}_{4}\right)$, chitosan, sodium alginate, and doxorubicin hydrochloride (DOX). They verified the composite PTT properties using an MTT assay with human lung cancer cell line (A549) and irradiation of $808 \mathrm{~nm}$ for $5 \mathrm{~min}$, demonstrating excellent intracellular uptake characteristics and dependence of the increase in temperature with the concentration. The best result shows a reduction of the survival rate to $14.36 \%$ with a dose of $100 \mu \mathrm{g} / \mathrm{mL}$ [66]. Furthermore, in the study by Huang and coworkers (2019), they developed a composite with indocyanine green (IR820), lactobionic acid (LA), DOX, and GO. They compared the photothermal capabilities of the composite and single GO, verifying a better performance of the composite due to an increase in temperature of $16.6{ }^{\circ} \mathrm{C}$ and $8.2^{\circ} \mathrm{C}$, respectively, after $5 \mathrm{~min}$ of irradiation of $660 \mathrm{~nm}$ [67]. These results can be seen in Figure 4.

A

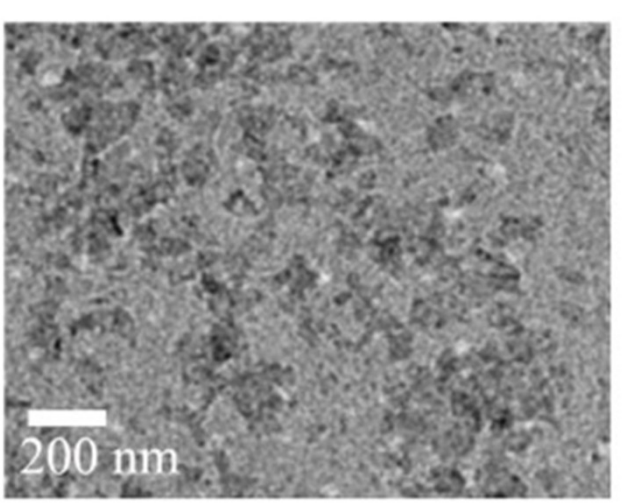

C

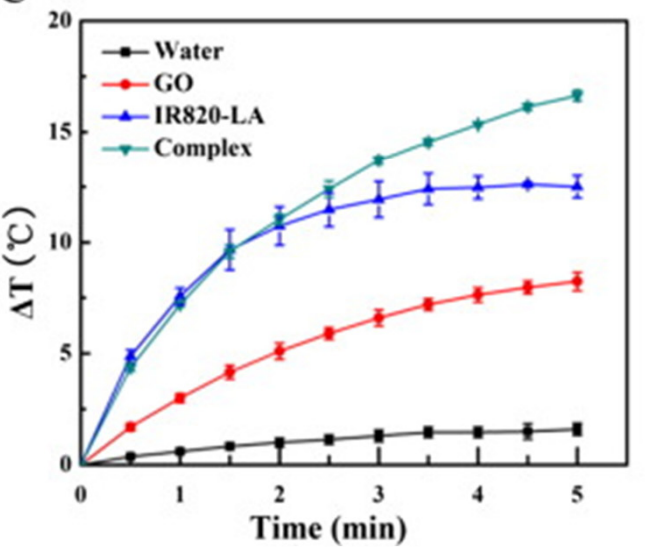

B

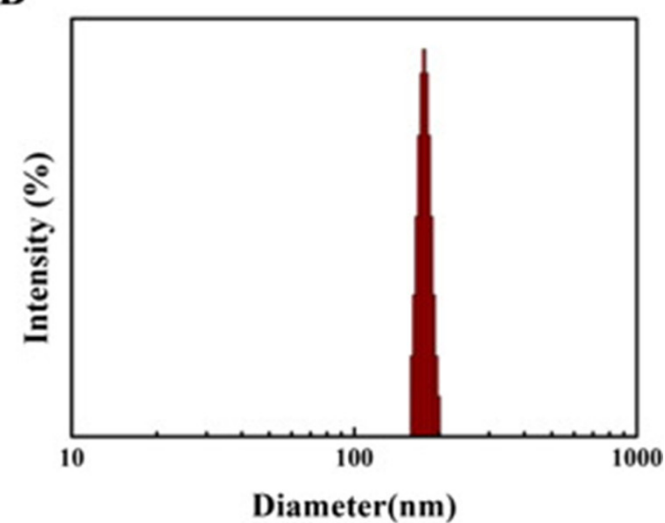

D

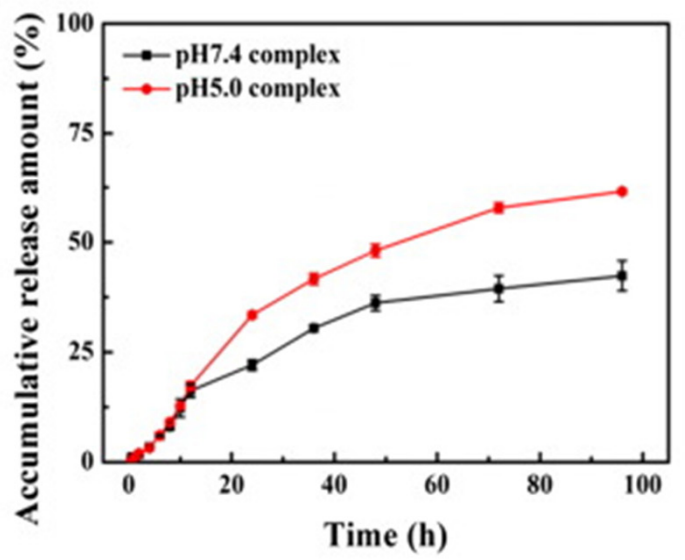

Figure 4. (A) TEM image of the composite; (B) Composite particle size distribution (DLS); (C) Photothermal effect curves of the composite, IR820-LA, GO, and water under a $660 \mathrm{~nm}$ laser $(n=3)$; and (D) In vitro DOX drug release of the composite. Complex* correspond to GO/DOX/IR820-LA composite. Reproduced from Ref. [67]. Copyright 2019 ELSEVIER.

\subsubsection{Application of GO in Synergistic Therapy}

A synergistic effect is the result of two or more processes interacting to produce a greater action than the individual ones. The assembly of composites through different materials with complementary properties allows its application in synergistic therapy. Several authors have studied the PDT/PTT synergistic effect of GO-based nanocomposites [68,69]. Gulzar et al. (2018) fabricated a hybrid with GO, amino-modified upconversion nanoparticles $\left(\mathrm{NaGdF}_{4}: \mathrm{Yb}^{3+} / \mathrm{Er}^{3+} @ \mathrm{NaGdF}_{4}: \mathrm{Nd}^{3+} / \mathrm{Yb}^{3+}\right)$, polyethylene glycol (PEG), and Chlorin e6 (Ce6). Singlet oxygen generation was confirmed through the DPBF (1,3-diphenyliso-benzofuran) chemical probe (PDT effect). In addition, an in vivo anti- 
tumor property was evaluated in mice using a U14 (murine hepatocarcinoma) cell line with irradiation of $808 \mathrm{~nm}$. As a result, the variation in the relative volume of the tumor $\left(\mathrm{V} / \mathrm{V}_{\mathrm{o}}\right)$ was reduced by half after 14 days as a consequence of the PTT effect, while this value in the control group increased by nine times [70]. Zhang et al. (2019) tested PDT, PTT, and chemotherapeutic effects of a composite fabricated with GO, wedelolactone, and indocyanine green. Under NIR irradiation $(808 \mathrm{~nm})$, ROS (singlet oxygen) generation was confirmed by DCFH-DA probe in human cervical carcinoma cells (HeLa cells). Moreover, stable and the reaching of high heat levels were proved $\left(\sim 79{ }^{\circ} \mathrm{C}\right)$ in comparison to the individual components $\left(\sim 33^{\circ} \mathrm{C}\right)$ [71]. Romero et al. (2021) functionalized the GO surface modified with PEG-folic acid, rhodamine B, and indocyanine green to treat Ehrlich tumors in mice by in vivo experiments using PDT and PTT with an NIR light of $808 \mathrm{~nm} 1.8 \mathrm{~W} / \mathrm{cm}^{2}$. Based on fluorescence images of the tumor, the highest concentration of GO as a function of the time after intraperitoneal injection was determined [72].

A basic scheme of the procedure to apply GO in synergistic therapy is shown in Figure 5.

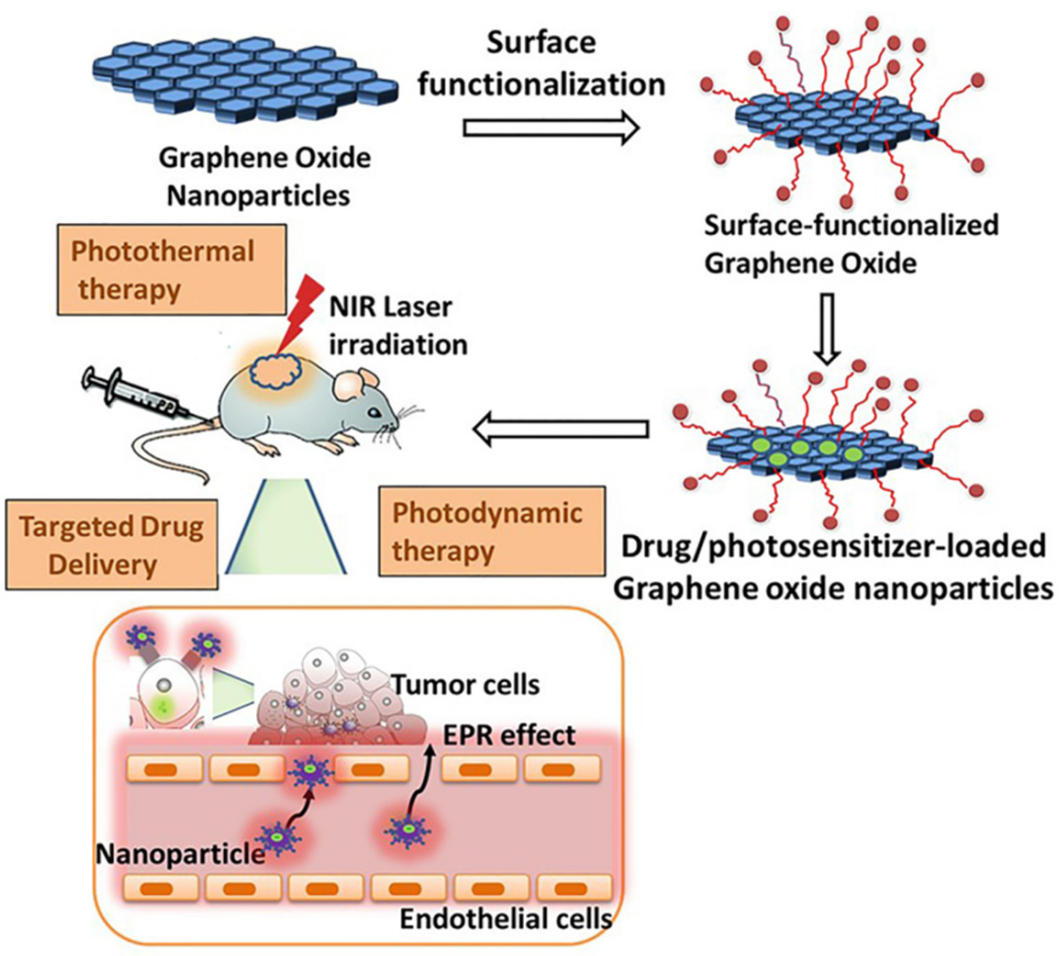

Figure 5. Procedure to apply GO-based hybrids/composites in PDT, PTT, and targeted drug delivery. EPR: enhanced permeability and retention. Reproduced from Ref. [58]. Copyright 2020 MDPI.

\subsection{Reduced Graphene Oxide ( $r-G O)$}

$\mathrm{r}-\mathrm{GO}$ is a material that exhibits excellent graphene-like properties. Generally, it is obtained from GO by some methods. Thermal, chemical, photocatalytic, laser, and electrochemical treatments, among others, have been developed to carry out the reduction from GO to r-GO [73]. Figure 6 presents the thermal reduction of GO to r-GO at different temperatures. In these procedures, functional groups are removed from the GO surface, and a structure similar to graphene is achieved with some imperfections and different magnitudes. The $\mathrm{C} / \mathrm{O}$ ratio is the primary indicator used to verify the quality of the GO reduction $[56,74]$. 

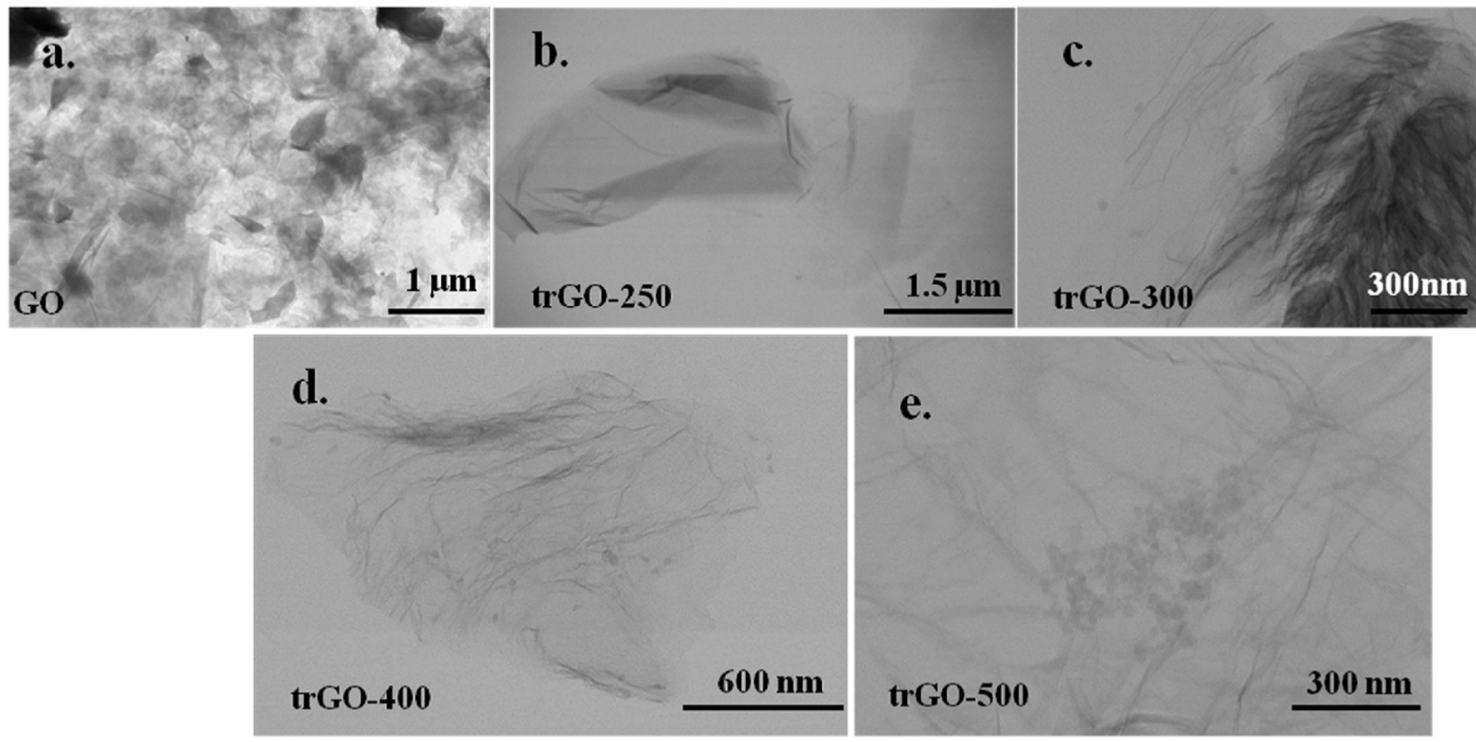

Figure 6. TEM images of (a) GO; and its reduction to r-GO at different temperatures: (b) $250{ }^{\circ} \mathrm{C}$, (c) $300{ }^{\circ} \mathrm{C}$, (d) $400{ }^{\circ} \mathrm{C}$, and (e) $500{ }^{\circ} \mathrm{C}$. Reproduced from Ref. [73]. Copyright 2020 ELSEVIER.

Several applications such as catalysts, membranes, super-capacitors, flexible sensors, bio-applications, and more, are based on r-GO [75]. Regarding the latter, specifically in phototherapy, r-GO is considered an excellent PS due to its ability to absorb visible and near-infrared ranges over the whole spectrum. Within cancer disease treatment, r-GO can be functionalized using conjugated molecules that can be employed as a drug delivery platform. Thus, r-GO has been employed in some therapies against cancer, as shown in Figure 7.

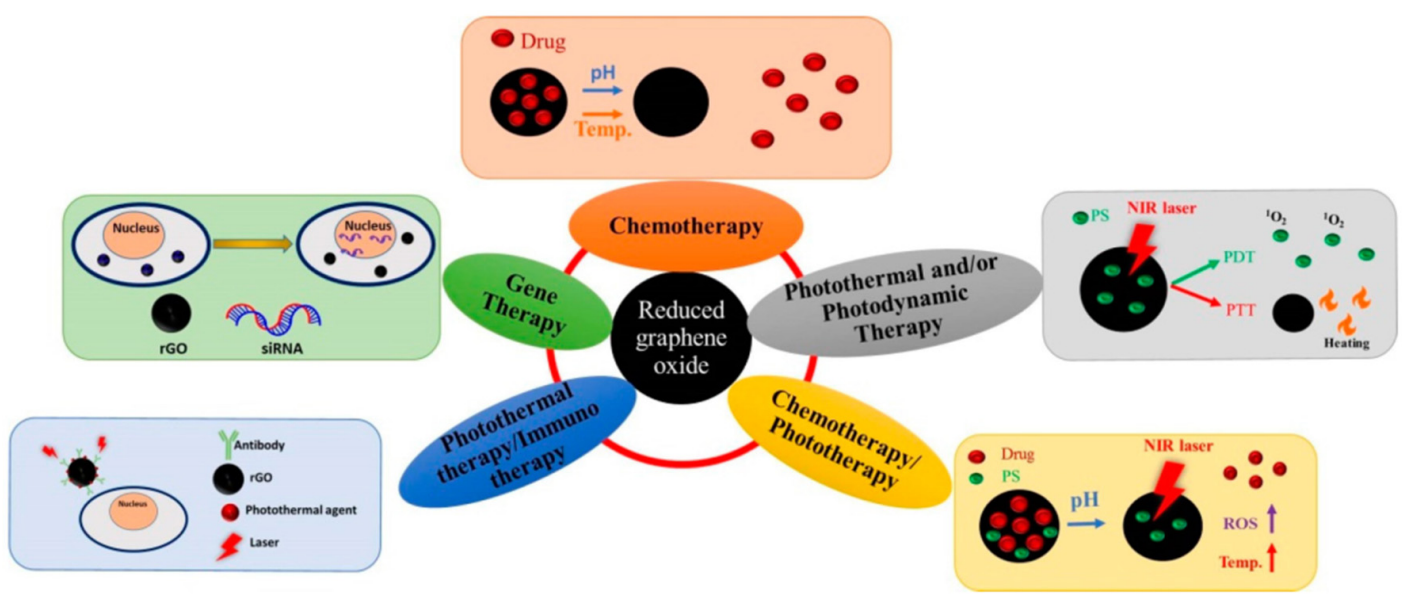

Figure 7. Applications of r-GO in PDT and PTT, chemotherapy/phototherapy, photothermal/immune therapy, gene therapy, and chemotherapy. Reproduced from Ref. [76]. Copyright 2021 MDPI.

\subsubsection{Application of $\mathrm{r}-\mathrm{GO}$ in PDT}

Vastly elaborate hybrids have been developed in the last few years to improve the r-GO solubility and selectivity in PDT applications. Thus, Kapri and Bhattacharyya (2019) synthesized a composite with nitrogen-doped r-GO, molybdenum sulfide, manganese dioxide, and PEG to test its photodynamic properties against cancer. They employed the MTT assay with HeLa cells and human embryonic kidney (HEK 293) cells. With a high dose of $200 \mu \mathrm{g} / \mathrm{mL}$ of the composite, the cell viability reached $\sim 85 \%$ for both cases. They used NIR irradiation of $980 \mathrm{~nm}$, achieving a disproportionation production 
of intracellular $\mathrm{H}_{2} \mathrm{O}_{2}$ turning this composite to an enhanced PS [77]. Likewise, Vinothini and coworkers (2020) developed an r-GO-based composite with magnetic nanoparticles $\left(\mathrm{Fe}_{3} \mathrm{O}_{4}\right)$, camptothecin, 4-hydroxycoumarin, and allylamine, to evaluate its photodynamic capability. They demonstrated high ROS generation and consequently good inhibition against MCF-7 cells (human breast cancer cell lines) under $365 \mathrm{~nm}$ of laser irradiation [78]. Green approaches have also been proposed for this. Jafarirad et al. (2018) fabricated three hybrids with $\mathrm{r}-\mathrm{GO}$, zinc oxide $(\mathrm{ZnO})$, neodymium $(\mathrm{Nd})$, and silver $(\mathrm{Au})$ nanoparticles ( $\mathrm{ZnO} / \mathrm{r}-\mathrm{GO}, \mathrm{Nd}-\mathrm{ZnO} / \mathrm{r}-\mathrm{GO}$, and $\mathrm{Ag}-\mathrm{ZnO} / \mathrm{r}-\mathrm{GO}$ ) using a rosehip extract (Rosa canina $\mathrm{L}$.) as a stabilizing and reducing agent. They satisfactorily demonstrated its antitumor capability employing 630 and $810 \mathrm{~nm}$ wavelengths of irradiation [79].

\subsubsection{Application of $\mathrm{r}-\mathrm{GO}$ in $\mathrm{PTT}$}

r-GO has a good photothermal conversion response and can effectively produce an overheating effect when used with IR light. Lima-Souza et al. (2018) developed an r-GO nanocomposite using hyaluronic acid and poly maleic anhydride-alt-1-octadecene. The hyaluronic acid was carefully chosen due to its hydrophilic behavior and targeting capacity to $\mathrm{CD} 44$ receptors in the cancer cell's membrane. This formulation presented heat capacity since, after NIR irradiation, its temperature increased to $33^{\circ} \mathrm{C}$, which induced the cancer cell's death. In addition, enhanced cytocompatibility and stability were achieved in comparison to a single r-GO [80]. Likewise, a different light source as low-intensity LED has been tested in PTT. De Paula et al. (2020) employed red LED (640 nm) ablation to significantly decrease the tumor mass of mice (melanoma in B16F10 lineage cells) using an rGO-based treatment. On the first day, the mean volume of the tumor was $\sim 70 \mathrm{~mm}^{3}$, and after 8 days of treatment, it reduced to $\sim 40 \mathrm{~mm}^{3}$. Moreover, the immune response was verified by detecting the growth in CD8+ T cells [81]. Liu et al. (2019) developed an elaborate hydrogel with carboxymethyl chitosan (CMC), r-GO, aldehyde (CHO), and PEG (see Figure 8). They assessed its photothermal effect and controllable DOX release under $808 \mathrm{~nm}$ of irradiation. The composite's thermal behavior showed a notable improvement due to the presence of $\mathrm{r}-\mathrm{GO}$ since the temperature increased from $25{ }^{\circ} \mathrm{C}$ to $\sim 65^{\circ} \mathrm{C}$ after exposure to light, while, prescinding this $\mathrm{CBM}$, the temperature only reached $\sim 33^{\circ} \mathrm{C}$ [82].

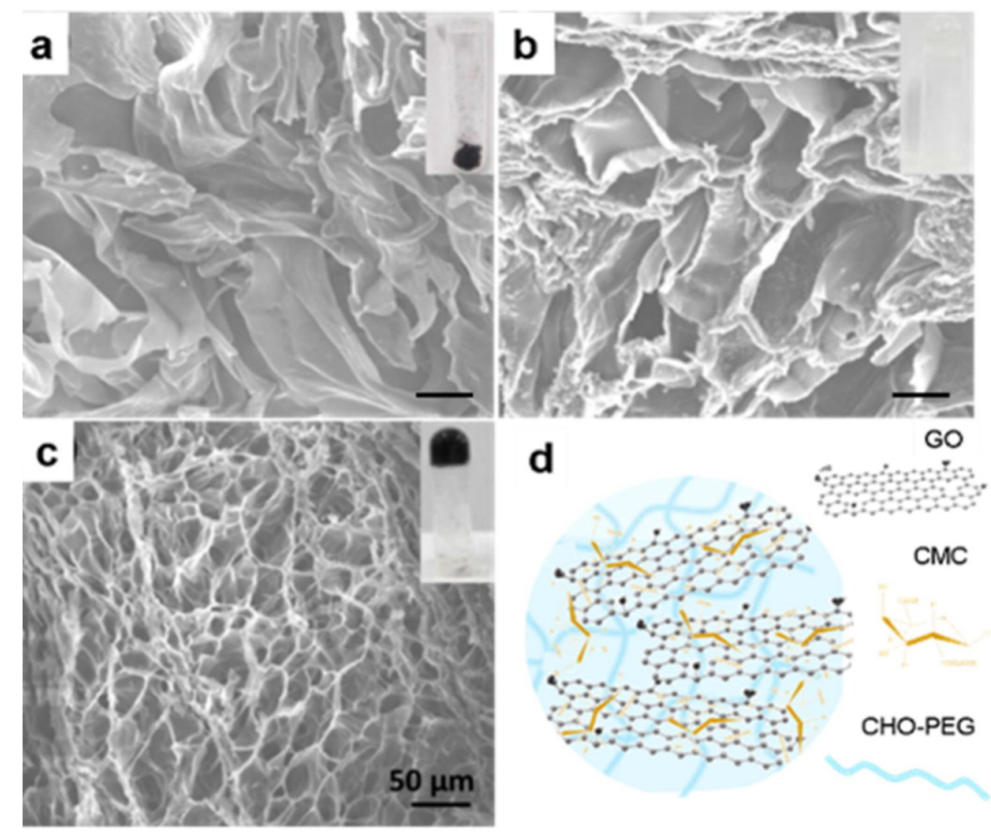

Figure 8. SEM images of: (a) CMC/r-GO powder; (b) CMC/CHO/PEG hydrogel; (c) CMC/ r-GO/CHO/PEG hydrogel; and (d) illustration of CMC/r-GO/CHO/PEG hydrogel. The insets show photographs of the corresponding samples. Reproduced from Ref. [82]. Copyright 2019 from ELSEVIER. 


\subsubsection{Application of r-GO in Synergistic Therapy}

Concerning synergist therapy, Zaharie-Butucel et al. (2019) combined PDT, PTT, and chemotherapy using a composite of r-GO, chitosan, IR820, and DOX. Its anticancer activity was satisfactorily assessed by cell proliferation assay against C26 cells (murine colon carcinoma) under NIR irradiation of $785 \mathrm{~nm}$. In addition, the authors demonstrated that the composite penetrated the cytoplasm and the nucleus using scanning confocal Raman microscopy. The composite was the tracker of the living cells, owing to the underlying lattice of the r-GO [83]. Wang et al. (2020) studied photothermal action and used an r-GO/PEG$\mathrm{NH}_{2} / \mathrm{Fe}_{3} \mathrm{O}_{4}$ composite under irradiation of $805 \mathrm{~nm}$ to eliminate primary tumors. Moreover, this nanomaterial encouraged antitumor immunity [84]. Likewise, Wei G. et al. (2016) evaluated PDT and PTT characteristics of an elaborate composite fabricated from r-GO, graphene diazotized, polyethylenemine, and tetrakis (4-carboxyphenyl) porphyrin against CBRH7919 cancer cells inducing apoptosis after irradiation due to singlet oxygen and heat generation [85]. Zhang et al. (2017) treated A549 lung cancer cells using two different light sources of $808 \mathrm{~nm}$ and $450 \mathrm{~nm}$ to PTT and PDT, respectively. As PS, they used a composite based on r-GO along with PEG-modified Ru (II) complex. This combination resulted in better cytotoxicity and an enhanced reduction in tumor volume, which was observed from in vivo tests. The PTT-PDT treatment inhibits the growth of the tumor, reducing the relative tumor volume value $\left(\mathrm{V} / \mathrm{V}_{\mathrm{o}}\right)$ close to zero, in contrast to the PTT and PDT alone, which showed an increase in this value to $\sim 1.5$ and $\sim 2.5$, respectively [86]. The results of the mentioned work are presented in Figure 9.

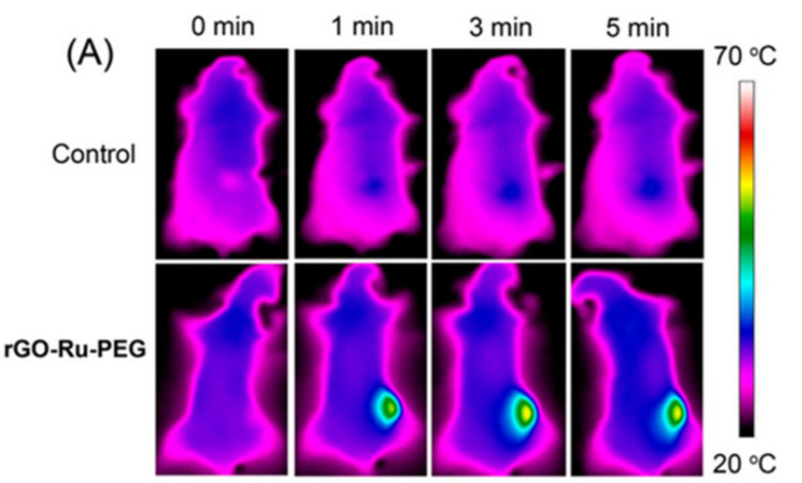

(B)

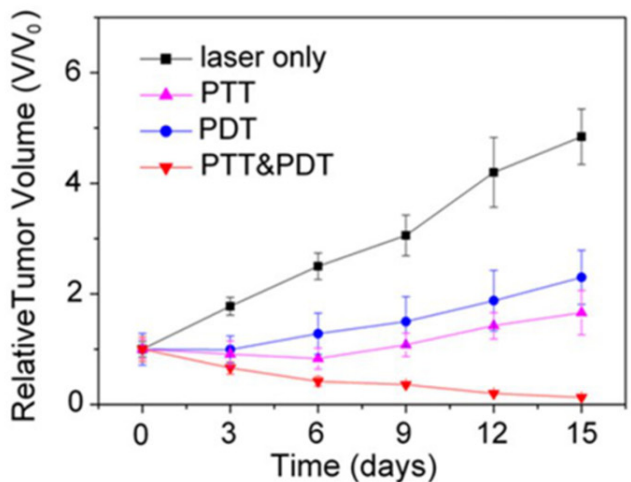

(C)

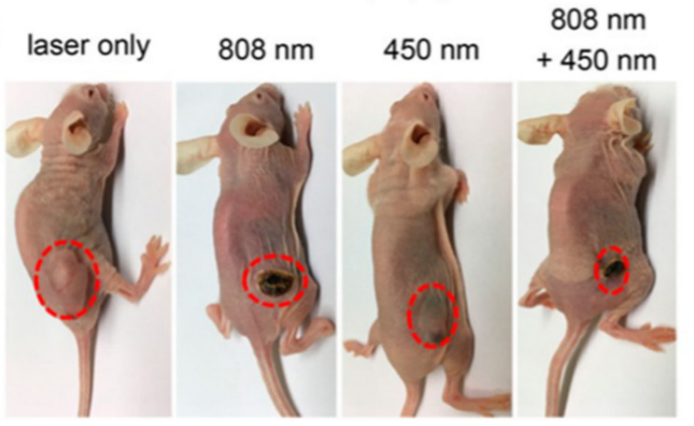

Figure 9. (A) IR thermal images of A549 tumor-bearing mice exposed to $808 \mathrm{~nm}$ laser for $5 \mathrm{~min}$. (B) Tumor growth curves of different groups of A549 tumor-bearing mice $(n=5)$. (C) Photos of mice after various treatments taken on day 15. Reproduced from Ref. [86]. Copyright 2017 ACS.

\subsection{Graphene Quantum Dots (GQDs)}

The zero-dimensional GQDs are emerging graphene derivatives. Their thickness, less than $100 \mathrm{~nm}$, consists of a maximum of 10 stacked layers of graphene sheets. These reduced dimensions trigger quantum confinement and special edge effects [53,87]. Due to the low toxicity, biocompatibility and photostability, GQDs have many applications such as cell imaging, drug carrier, biosensors, and so on [88]. 
In order to expand the narrowed visible photoluminescence of GQDs to all visible and infrared, nitrogen doping has been considered [89]. GQDs have also been employed in several phototherapy studies [90,91], including PDT and PTT. GQDs were used as single photo absorbing agents or in the development of composites [92].

A scheme of the inherent effects, preparation methods, properties, and applications of GQDs is presented in Figure 10.

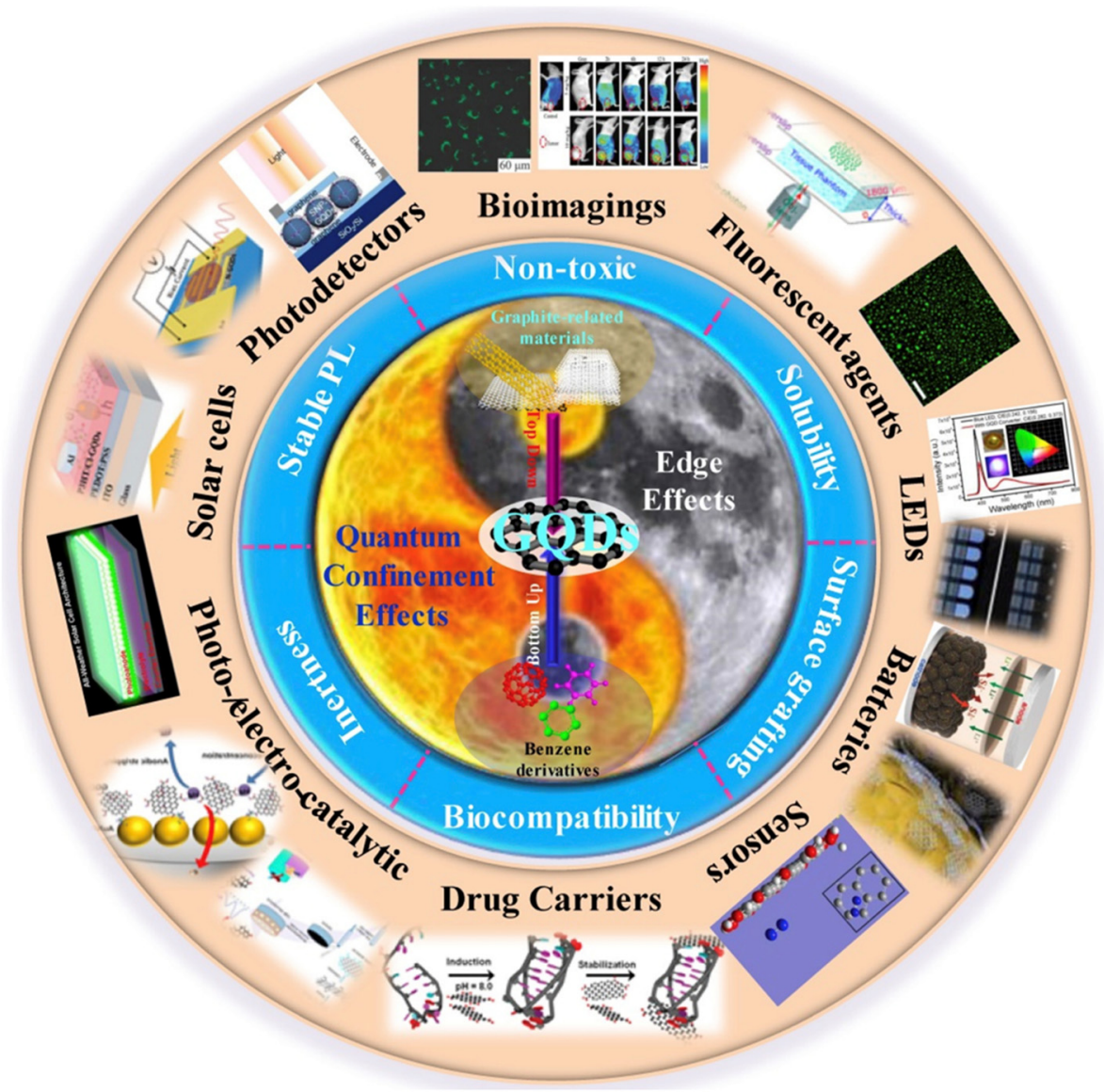

Figure 10. GQDs related inherent effects, preparation methods, properties, and applications. Reproduced from Ref. [53]. Copyright 2018 ELSEVIER.

\subsubsection{Application of GQDs in PDT}

Ge et al. (2014) fabricated GQDs from $2 \mathrm{~nm}$ to $6 \mathrm{~nm}$ in diameter, which showed ROS generation capability and was employed within in vivo experiments. After 9 and 17 days of treatment of female BALB/c mice with GQDs, a reduction of the tumor was verified [93]. Tabish et al. (2018) synthesized 20 nm GQDs with a 7.1\% yield and demonstrated its ROS generation under irradiation of $365 \mathrm{~nm}$. In addition, limited toxicity was verified by in vitro and in vivo tests [94]. Campbell et al. (2021) developed a nanocomposite based on three covalently bounded components: nitrogen-doped GQDs, hyaluronic acid, and ferrocene. The composite did not present a significant cytotoxic response at concentrations of up to $1 \mathrm{mg} / \mathrm{mL}$ for HEK-293 cells, greater than $90 \%$ in cell viability. In contrast, the composite action against HeLa cells promoted better cytotoxicity, up to $20 \%$ after $72 \mathrm{~h}$. Moreover, therapeutic ROS generation was three times higher than that of single ferrocene [95]. It is worth noting that the performance of GQDs in PDT might be associated with its specific structural features. Chen et al. (2020) examined the photoactivity of single-atomic-layered GQDs under laser and halogen irradiation, demonstrating a null generation of ${ }^{1} \mathrm{O}_{2}$, which was attributed to its particular morphology [96]. 
On the other hand, regarding the doping of GQDs, it has been considered to improve its phototherapy performance. Elements like sulfur and nitrogen have been employed to achieve this aim. Concerning the latter, some studies have determined that nitrogenbonding increased ROS generation compared to single GQDs [97,98].

\subsubsection{Application of GQDs in PTT}

PTT studies have also evaluated irradiations below the second NIR window (1000-1700 nm) to improve penetration and enhance the damage of the tumor. As a result, Liu et al. (2020) fabricated $3.6 \mathrm{~nm}$ GQDs and assessed their photothermal properties under $1064 \mathrm{~nm}$ wavelength. In vitro and in vivo tests demonstrated that GQDs killed tumor cells and inhibited tumor growth, respectively [99]. Yao et al. (2017) studied the heat generation of magnetic mesoporous silica nanoparticles capped with GQDS under an alternating magnetic field and NIR irradiation. This material showed efficient PTT and magnetic hyperthermia in in vitro experiments [100]. Wang et al. (2019) synthesized GQDs doped with nitrogen and boron and analyzed the composite under NIR-II region. In vitro and in vivo tests demonstrated the photothermal effect using a glioma xenograft mouse model [101]. Li et al. (2017) loaded IR780 dye on folic acid (FA) functionalized GQDs and studied their behavior under irradiation of $808 \mathrm{~nm}$ for $5 \mathrm{~min}$. The temperature of a mice tumor was raised to $58.9{ }^{\circ} \mathrm{C}$, and in vivo antitumor experiment presented a suppressive effect on tumor growth, dissipating it in 15 days, as can be seen in Figure 11 [102].

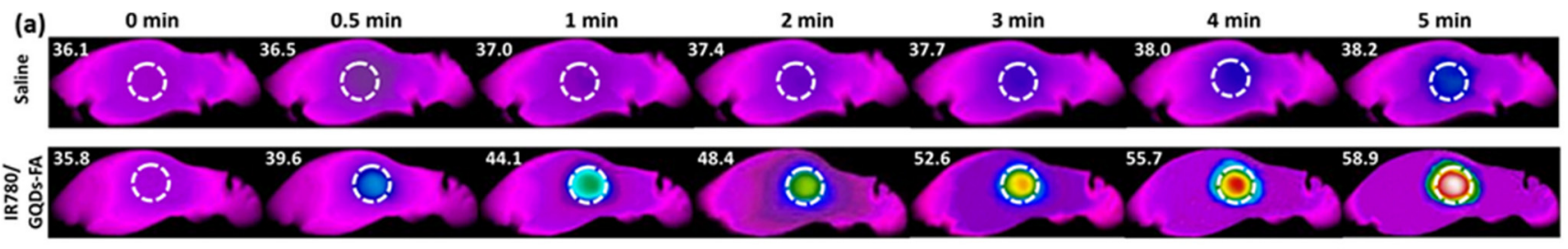

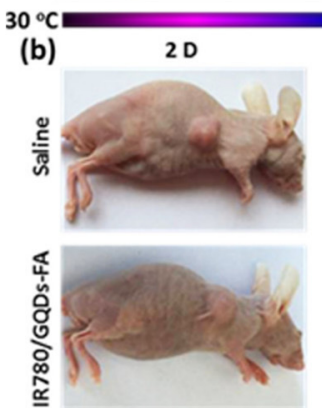

(e) Heart
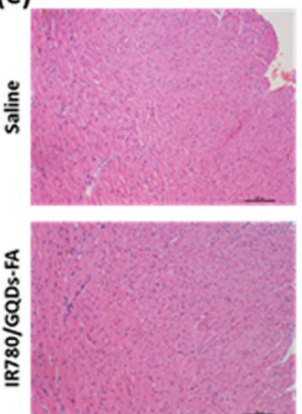

$8 \mathrm{D}$

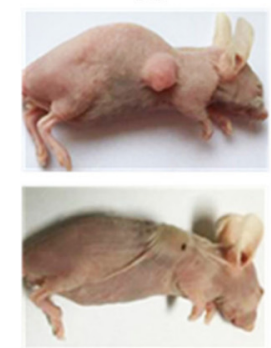

Liver

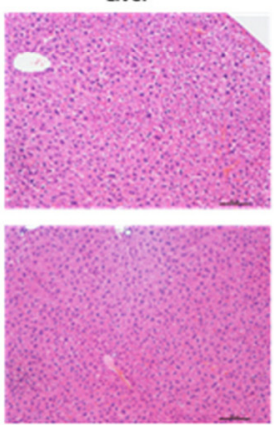

$15 \mathrm{D}$

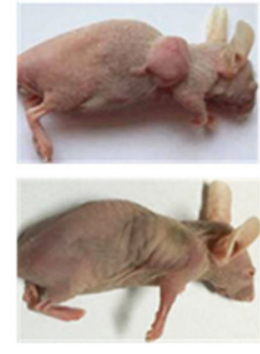

Spleen

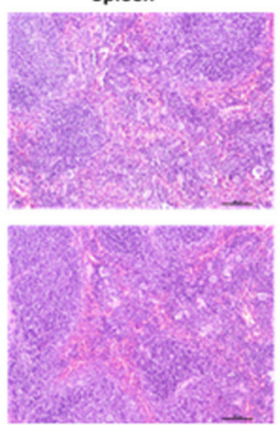

(c)

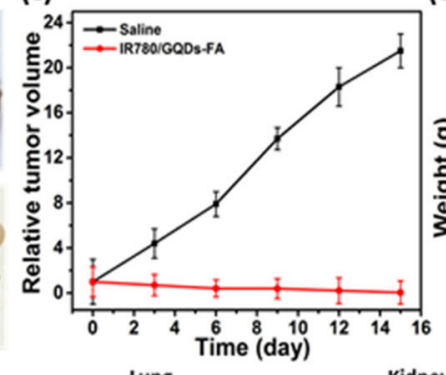

Lung

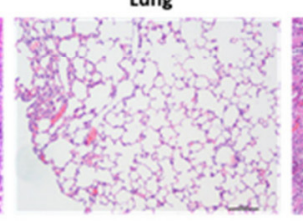

Kidney

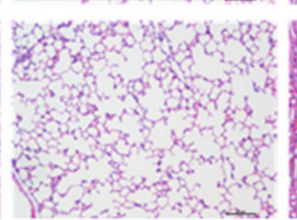

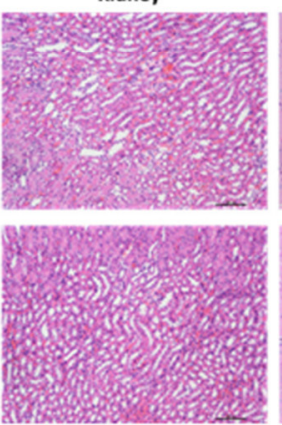

(d)

$60^{\circ} \mathrm{C}$

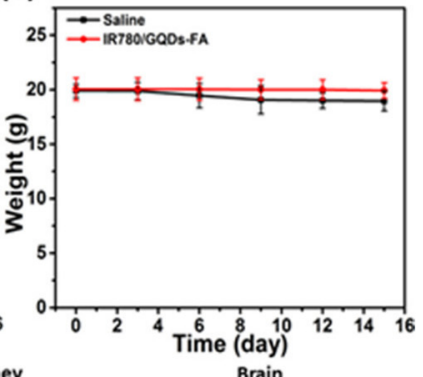

Brain

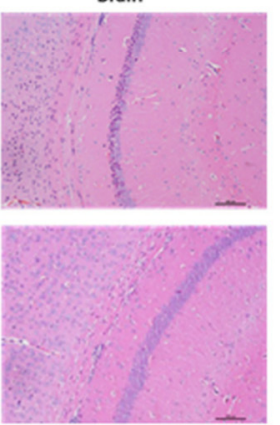

Figure 11. (a) Tumor thermal images of temperature variations after intravenous injection of saline and IR780/GQDs-FA with laser irradiation; (b) Photos of the tumor-bearing mice after treatments. Tumor volume (c) and body weight (d) curves of the tumor-bearing mice. (e) Histological evaluation of tissues from the mice treated with saline and IR780/GQDs-FA. Each organ was sliced for hematoxylin and eosin (H\&E) staining. Reproduced from Ref. [102]. Copyright 2017 ACS. 


\subsubsection{Application of GQDs in Synergistic Therapy}

Synergistic therapy has also been studied employing GQDs. Wang and coworkers (2020) developed a composite with cRGD (Cyclic Arg-Gly-Asp peptide) and DOX to evaluate its photothermal activity against SK-mel-5 and H460 cells under NIR irradiation of $808 \mathrm{~nm}$. Furthermore, its chemotherapy capacity was verified, demonstrating an IC50 reduction up to $39.63 \mu \mathrm{g} / \mathrm{mL}$ and $53.75 \mu \mathrm{g} / \mathrm{mL}$, respectively [103]. Likewise, Zheng et al. (2019) developed a composite with GQDs, DOX, and hollow copper sulfide nanoparticles within photothermal-chemotherapy applications using NIR irradiation on MDA-MB-231 cells. This research demonstrated a high therapeutic effect in tumor cells and its potential in cancer therapy [104]. To evaluate its NIR response, Thakur et al. (2017) produced GQDs using waste as a carbon source (see Figure 12), specifically withered leaves of Ficus racemose (Indian fig tree). They demonstrated that GQDs were cytocompatible employing cell cycle analysis by flow cytometry and biocompatibility studies. Moreover, it was demonstrated that upon irradiation of $808 \mathrm{~nm}$ wavelength $\left(0.5 \mathrm{~W} \mathrm{~cm}^{-2}\right)$, the concentration dependence of photothermal response and the production of reactive oxygen species were achieved [105].
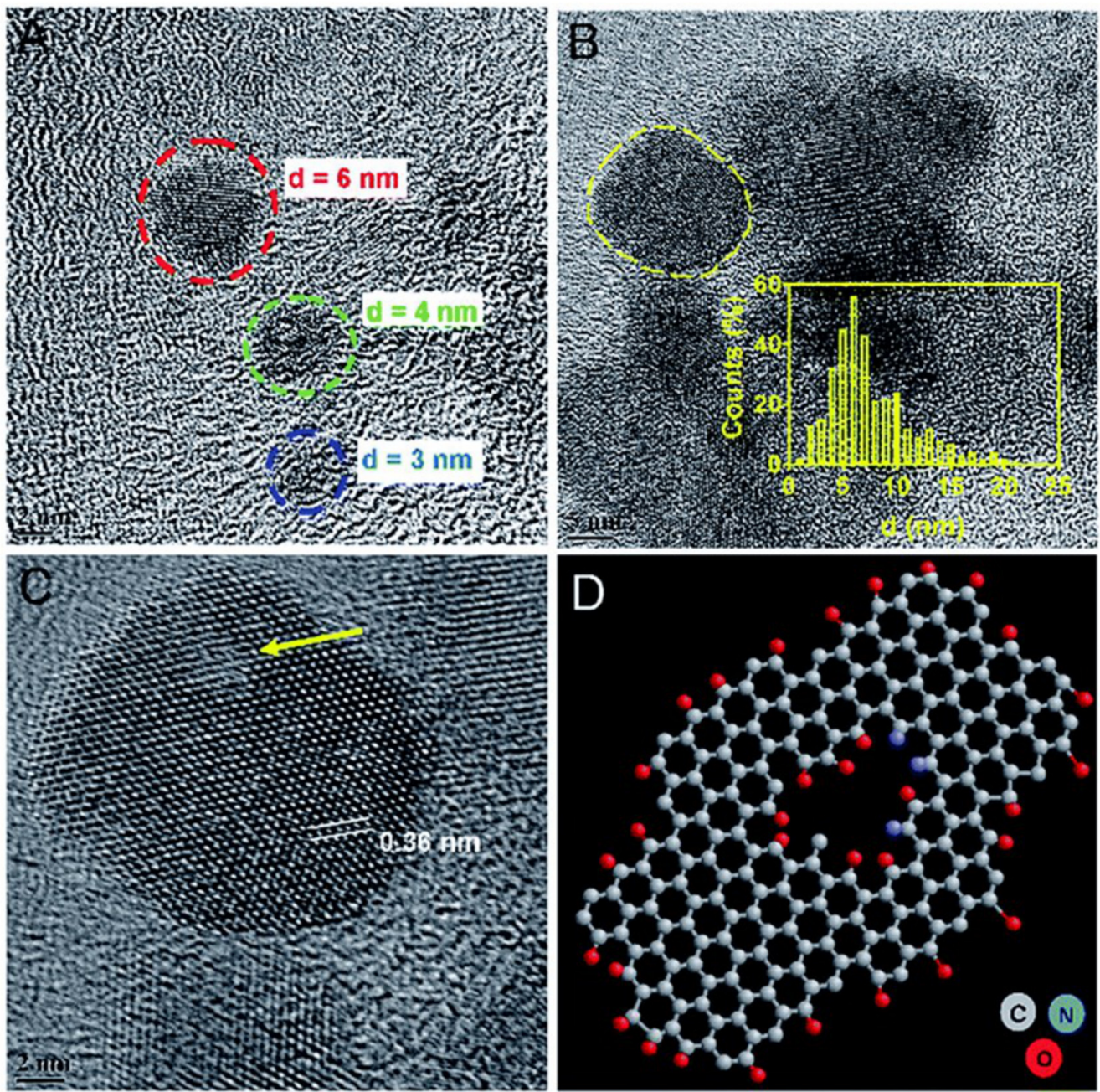

Figure 12. Morphological analysis of GQDs from withered leaves. TEM image of (A) ultra-small GQDs and (B) existence of GQDs in cluster form with inset showing size distribution. (C) HRTEM of a single crystalline GQD (marked in (B)) with a honey-comb-like structure of graphene with few basal/edge state-defects shown with an arrow. Inset here shows lattice spacing distance. (D) Ball and stick model indicating the defect in a typical structure of GQD with self-passivated functional groups. Reproduced from Ref. [105]. Copyright 2017 Royal Society of Chemistry. 


\subsection{Carbon Dots (C-DOTs)}

C-DOTs can be generally defined as a quasi-0D carbon-based material with sizes below $10 \mathrm{~nm}$. These materials have spherical or hemispherical structures corresponding to a core of carbon atoms with hybridization inter $\mathrm{sp}^{2}$ whose surface is functionalized $[106,107]$. C-DOTs, new rising stars in the carbon family, have attracted substantial attention due to their excellent and tunable photoluminescence, high quantum yield, fluorescence, low toxicity, small size, appreciable biocompatibility, and abundant, low-cost sources, providing essential applications in many fields, including biomedicine, catalysis, optoelectronic devices, and anticounterfeiting [108-110].

C-DOTs have been deemed appropriate for phototherapy applications, not only as photo absorbing agents but also as nano-carriers. Several hybrids obtained by covalent coupling, electrostatic interaction, or $\pi-\pi$ stacking have been tested in recent years $[111,112]$.

\subsubsection{Application of C-DOTs in PDT}

The antitumor effect of C-DOTs conjugates within PDT to treat cancer disease has been confirmed by several authors. Li et al. (2017) prepared porphyrin-containing C-DOTs from mono-hydroxylphenyl triphenylporphyrin and chitosan through a simple one-pot hydrothermal method. They evidenced the effective photodynamic activity toward human hepatocellular liver carcinoma (HepG2) cells by MTT assay under LED irradiation of $625 \mathrm{~nm}$ for $1 \mathrm{~h}$. With a concentration of $0.5 \mathrm{mg} / \mathrm{mL}$, cells presented lysis, dramatic apoptosis, and membrane disruption. Their results show that the material possesses good photostability, biocompatibility, cellular uptake, and potent cytotoxicity upon irradiation. In the in vivo test, the size of the irradiated mice tumor was reduced from 100 to $56 \mathrm{~mm}^{3}$, while without irradiation, an increment in the tumor size to $\sim 800 \mathrm{~mm}^{3}$ was detected [113]. Huang et al. (2012) prepared a novel theranostic system based on Ce6-conjugated C-DOTs. The in vitro results determine that the composite upon irradiation exhibits good stability and solubility, low cytotoxicity, good biocompatibility, enhanced photosensitizer fluorescence detection, and remarkable photodynamic efficacy compared to Ce6 alone. Furthermore, the in vivo results suggest that the newly synthesized nanocomposite possesses excellent imaging efficacy [114]. Qin et al. (2021) produced C-DOTs by microplasma using o-phenylenediamine, revealing a broad absorption peak at 380-500 $\mathrm{nm}$ and emitted bright yellow fluorescence with a peak at $550 \mathrm{~nm}$. The C-DOTs were rapidly taken up by HeLa cancer cells. A bright yellow fluorescence signal and intense ROS were efficiently produced when excited under blue light, enabling simultaneous fluorescent cancer cell imaging and photodynamic inactivation, with a $40 \%$ decrease in relative cell viability [115].

A simplified scheme of the production of ROS for PDT based on C-DOTs is shown in Figure 13.

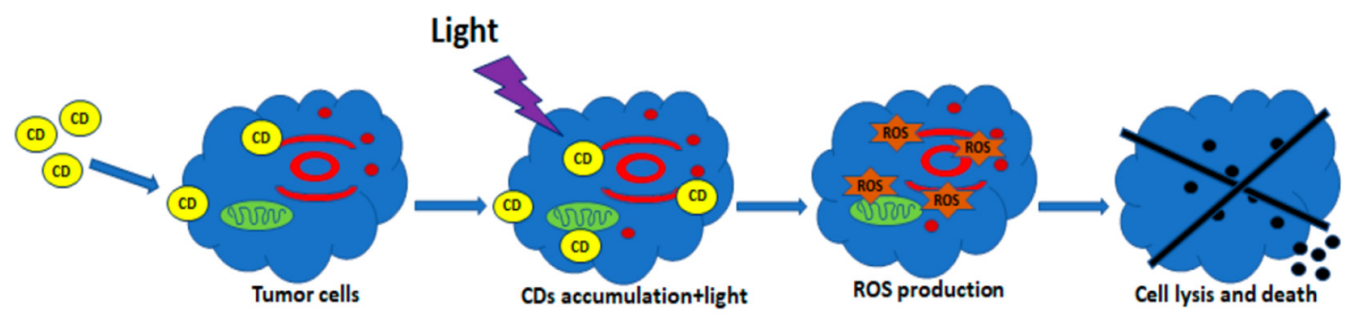

Figure 13. Schematic diagram of PDT. C-DOTs (CDs) penetrate the cell membrane and accumulate in the cytosol. Light irradiation actives and induces the production of ROS. Reproduced from Ref. [116]. Copyright 2021 MDPI.

\subsubsection{Application of C-DOTs in PTT}

The study by Meena and coworkers (2019) demonstrates that C-DOTs, synthesized from ayurvedic medicinal plants, with a concentration of $0.5 \mathrm{mg} / \mathrm{mL}$ and under $10 \mathrm{~min}$ of light exposure $(750 \mathrm{~nm})$, reached a temperature of up to $46^{\circ} \mathrm{C}$, verifying its potential on photothermal therapy. Furthermore, no significant toxicity was revealed against NIH-3T3 
normal cells, indicating attractive behavior in this field [117]. Sun et al. (2016) demonstrated that red emissive C-DOTs were able to efficiently and quickly convert laser energy into heat and that upon laser irradiation for $10 \mathrm{~min}$, the viability of MCF-7 cells was significantly reduced as the concentration increased (20-200 $\mu \mathrm{g} / \mathrm{mL})$ [118]. Geng et al. (2018) showed that NIR-absorbing nitrogen and oxygen co-doped C-DOTs generated high-efficiency heat under laser irradiation at a low power density achieving $100 \%$ of tumor ablation without causing any side effects [119]. Zheng et al. (2016) synthesized an NIR fluorescent composite (from $600 \mathrm{~nm}$ to $900 \mathrm{~nm}$ ) from a hydrophobic cyanine dye and PEG with preferential uptake and accumulation to tumors and high photothermal conversion efficiency (38.7\%) as a novel theranostic agent for NIR fluorescent imaging and PTT in vivo and in vitro [120]. Likewise, Li et al. (2019) developed a novel second near-infrared (NIR-II) emitting C-DOTs which had good photothermal efficiency of up to $30.6 \%$ under irradiation of $808 \mathrm{~nm}$. The detailed results of this work are presented in Figure 14 [121].

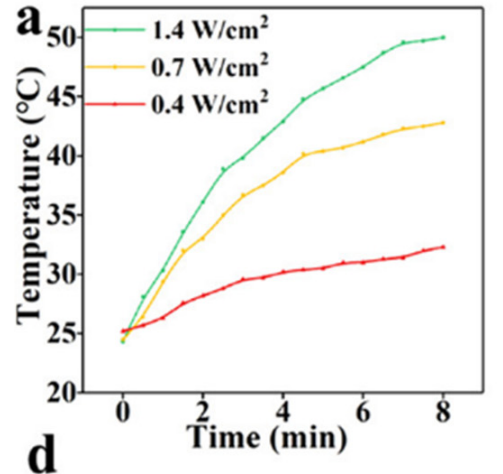

$0 \min 1 \min 2 \min 3 \min$

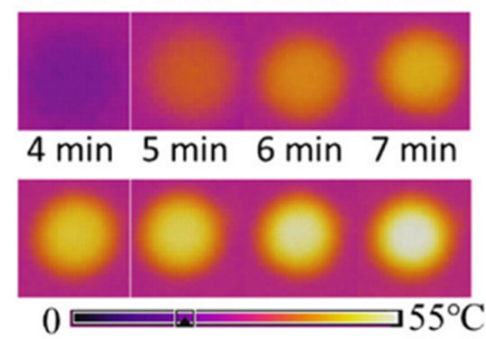

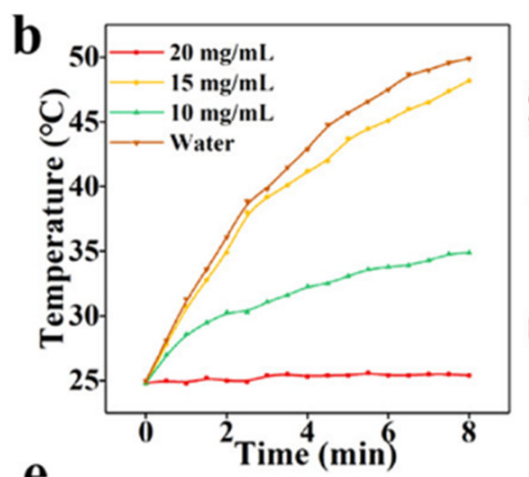
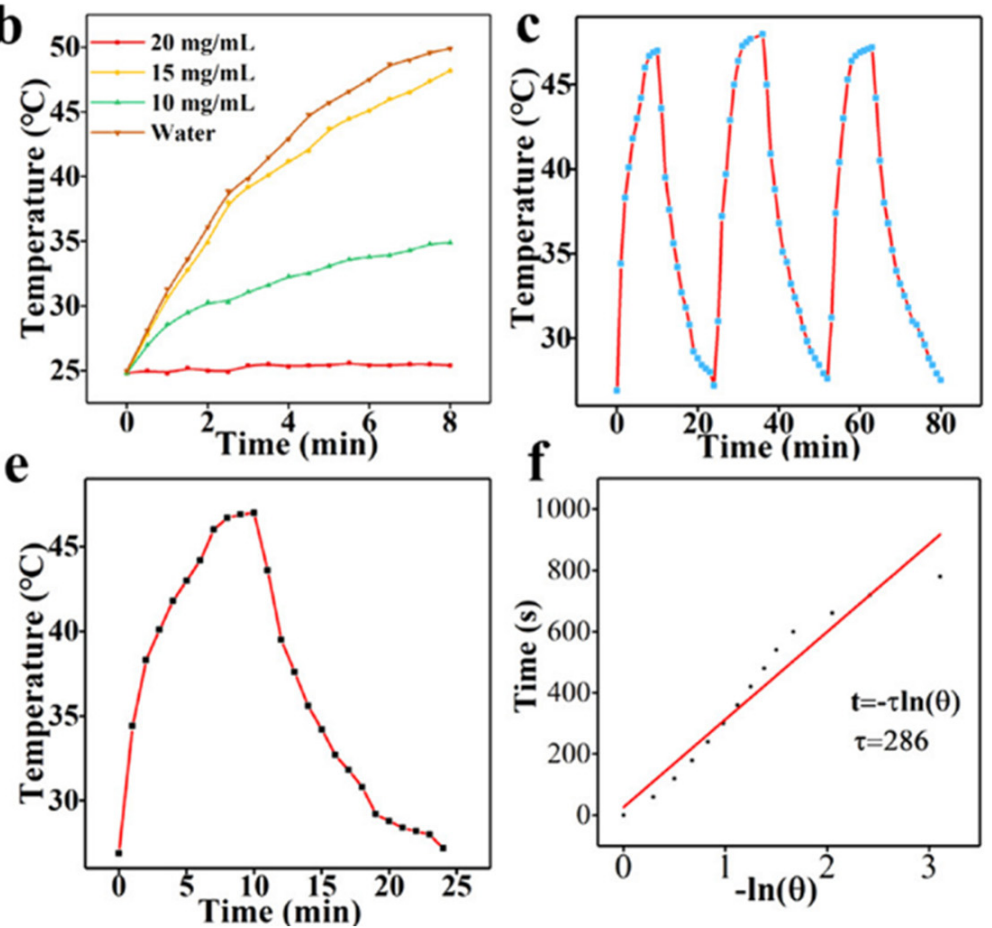

Figure 14. (a) Temperature curves of C-DOTs solution $(20 \mathrm{mg} / \mathrm{mL})$; (b) Temperature curves of different concentrations of C-DOTs solutions; (c) Photothermal profiles of C-DOTs solution with 3 irradiation cycles; (d) Thermal infrared images of C-DOTs solutions recorded after 7 min of irradiation; (e) Heating and cooling curves of C-DOTs solution; (f) Linear time data and $-\ln \theta$ acquired from a cooling period of (e). $1.4 \mathrm{~W} \mathrm{~cm}^{-2} ; 15 \mathrm{mg} / \mathrm{mL}$. Reproduced from Ref. [121]. Copyright 2019 ACS.

\subsubsection{Application of C-DOTs in Synergistic Therapy}

Jia et al. (2018) tested in vivo/in vitro PDT and PTT properties of green synthesized C-DOTs against HeLa cells under $635 \mathrm{~nm}$ of irradiation, demonstrating $0.38 \%$ of quantum yield and $27.6 \%$ of photothermal conversion efficiency [122]. It is worth noting that ROS and heat generation are desirable, but selectivity is essential. For example, besides cancer cells, lysosome targeting has also been assessed, showing promising results [123]. Furthermore, some studies have been published comprising synergistic therapy with multifunctional C-DOTs. Consequently, Lan et al. (2018) synthesized C-DOTs and confirmed their PDT and PTT activities under $800 \mathrm{~nm}$ of irradiation. In addition, their fluorescence and photoacoustic properties for imaging were verified [124]. Similar evaluations were carried out by Sun et al. (2019) using amino C-DOTs modified with $0.56 \%(w / w)$ of Ce6, but with irradiation of $671 \mathrm{~nm}$ [125]. In this context, Guo and coworkers (2018) developed 
$\mathrm{Cu}, \mathrm{N}$-doped C-DOTs using different temperatures in a simple hydrothermal method. They evaluated the PDT and PTT capabilities under $808 \mathrm{~nm}$, determining ROS generation and a rise in temperature of up to $53{ }^{\circ} \mathrm{C}$ [126]. Zhang et al. (2018) synthesized a therapeutic agent from DOX loaded in a conjugated sgc8c aptamer $\left(5^{\prime}\right.$-NH2-TGA ATG TTG TTT TTT CTC TTT TCT ATA GTA-3'), with single-walled carbon nanotubes (SWCNTs), PEG, $\mathrm{Fe}_{3} \mathrm{O}_{4}$, and carbon quantum dots with a multifunction ability that can target and kill cancer cells by releasing the drug photodynamically or photothermally. The composite converted $808 \mathrm{~nm}$ NIR into heat energy, generated ROS, and removed cancer cells. These nano-carriers are favorable for treating cervical cancer and other diseases that need precise drug targeting [120]. Yang et al. (2019) synthesized C-DOTs/Hemin. The composite could increase the temperature enhancement to $26^{\circ} \mathrm{C}$ under laser irradiation with outstanding photodynamic efficacy. More than $90 \%$ of cancer cells die after $10 \mathrm{~min}$ laser treatment. This hybrid showed high ROS generation using the DCFH-DA probe against HepG2 cells [127].

A simplified scheme of ROS production for PDT and heat for PTT therapies based on C-DOTs is shown in Figure 15.

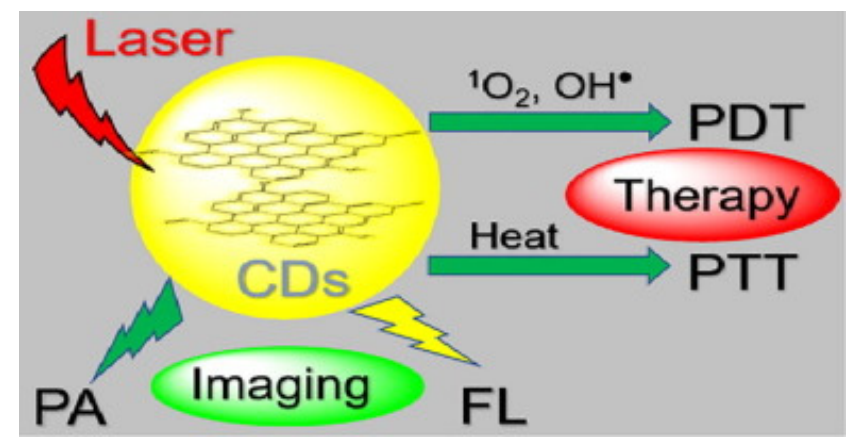

Figure 15. Lysosome targetable C-DOTS which can simultaneously generate ${ }^{1} \mathrm{O}_{2}, \mathrm{OH}^{\bullet}$, and heat under $635 \mathrm{~nm}$ laser irradiation. Reproduced from Ref. [123]. Copyright 2020 ELSEVIER.

\section{Advantages of CBM in PDT and PTT over Metal-Organic and Organic PSs}

The advantages of CBM have been assessed by a number of authors. Ge et al. (2014) evaluated the PDT efficiency and cytotoxicity against HeLa cells under irradiation of $630 \mathrm{~nm}$ for 10 min using GQDs and protoporphyrin IX (PpIX). Employing $0.036 \mu \mathrm{M}$ of GQDs, a cell viability of $60 \%$ was detected. This parameter was reduced when the GQD concentration was increased. Nevertheless, the survival of HeLa cells was not greatly influenced by GQDs, indicating its good biocompatibility and low cytotoxicity. In contrast, using $1.8 \mu \mathrm{M}$ of PpIX, a low cell viability of 55\% was achieved in the dark conditions, and more than $35 \%$ of the cells survived even upon irradiation. GQDs showed superior PDT efficiency compared to PpIX and lower cytotoxicity [93].

Ge et al. (2016) prepared C-DOTs using polythiophene benzoic acid as a carbon source. The degradation of disodium 9,10-anthracendipropionic acid ( $\mathrm{Na}_{2}$-ADPA) was confirmed by the generation of singlet oxygen from C-DOTs and the PS methylene blue. The quantum yield of the C-DOTs was calculated to be 0.27 , and the $\mathrm{MB}$ was 0.58 in $\mathrm{CD}_{3} \mathrm{OD}$ solutions, showing a significant difference between these values [128]. Shi et al. (2013) synthetized hyaluronic acid-derivatized carbon nanotubes (HA-CNTs) and studied the cell viability of B16F10 cells with different concentrations of HA-CNTs, the PS hematoporphyrin monomethyl ether (HMME), and the composite HMME-HA-CNTs based on PDT and PTT effect. They used light irradiation of $532 \mathrm{~nm}\left(100 \mathrm{~mW} / \mathrm{cm}^{2}\right)$ with HMME and nearinfrared $808 \mathrm{~nm}$ irradiation $\left(1.4 \mathrm{~W} / \mathrm{cm}^{2}\right)$ with HA-CNTs. It was shown that HMME exhibited relatively small cytotoxicity to B16F10 cells, while the HMME with $532 \mathrm{~nm}$ laser group greatly enhanced cytotoxicity. In contrast, HA-CNTs exhibited a stronger inhibition than HMME. HA-CNTs are superior to HMME in terms of both their PDT and PTT efficiency [129]. 
The efficiency of CBM gave way to the design of nanocomposites, leading to the theranostic effect, which allows for the observation of a higher concentration of CBM loading PS in the tumor in relation to PS alone (metal-organic or organic). PS is often limited because of reduced water solubility, photostability, prolonged cutaneous photosensitivity, and low selectivity [130].

The advantages of using nanoplatforms in theranostic CBM designs have been widely studied [59,131]. Xie L. et al. (2016) designed a long circulation multifunctional albumin/Ce6 loaded evans blue/carbon nanotube-based delivery system (ACEC) that showed synergistic PDT and PTT along with efficient tumor ablation effects using red and IR light of $630 \mathrm{~nm}$ and $800 \mathrm{~nm}$, respectively. In vivo fluorescence imaging and photoacoustic imaging of SCC7 tumor were developed and evidenced in the Ce6-only group that the signal was mainly distributed in the liver $8 \mathrm{~h}$ after treatment and disappeared $24 \mathrm{~h}$ after injection. The fluorescence images of the tumor regions gradually strengthened over time and reached their maximum point $(\mathrm{T} / \mathrm{M}$ ratio $=7.83 \pm 0.31)$ at $24 \mathrm{~h}$ post-treatment in the ACEC group and were gradually eliminated, indicating that ACEC circulated for a greater duration and accumulated more than the free Ce6 and albumin/Ce6. Compared to PDT or PTT alone, the combined phototherapy managed to damage the tumor and diminish the tumor without return [132]. Romero et al. (2021) designed theranostic nanocomposites based on GO with a surface modification of PEG-folic acid, rhodamine B, and indocyanine green $(\mathrm{GO}+\mathrm{RhodB}$, $\mathrm{GO}+\mathrm{PEGFA}+\mathrm{RhodB}$, and GO+PEGFA+ICG). In addition to displaying red fluorescence spectra rhodamine $B$ (as the fluorescent label), in vivo experiments were performed using GO to apply PDT and PTT in the treatment of Ehrlich tumors in mice using NIR light. The study was performed to obtain the highest concentration of GO in the tumor as a function of time (time after intraperitoneal injection). The obtained time was used to treat the tumor by PDT/PTT. Tumor volume control shows that the GO+PEGFA+ICG group has the lower "R factor" ((V-V $\left.\mathrm{V}_{\mathrm{o}} / \mathrm{V}_{\mathrm{o}}\right)$ normalized by day's number of follow-up) related to only the indocyanine group. Compared to PDT (only indocyanine PS) and PTT alone (only GO), the theranostic therapy diminished the tumor without recurrence (see Figure 16) [72].

Hua et al. (2018) synthetized C-DOTs via hydrothermal reaction of m-phenylenediamine and L-cysteine. The cytotoxicity of C-DOTs and the PS PpIX in HeLa cells were evaluated. The dark toxicity and the PDT efficacy of C-DOTs-PpIX and PpIX on the mentioned cells were confirmed. Free PpIX and C-DOTs-PpIX elicited no obvious cytotoxicity toward the cells after incubation for $24 \mathrm{~h}$ in the dark, indicating their excellent cytocompatibility. The PDT effect based on photoexcitation was studied and C-DOTs-PpIX showed more efficient cell-killing ability than free PpIX as the cell viability of C-DOTs-PpIX group was much lower than that of the free PpIX group [133].

Thus, nanoplatforms in theranostic CBM show advantages over organic and metalorganic PS due to their greater effectiveness and greater possibility of altering the molecule, thus increasing stability and biological availability. 

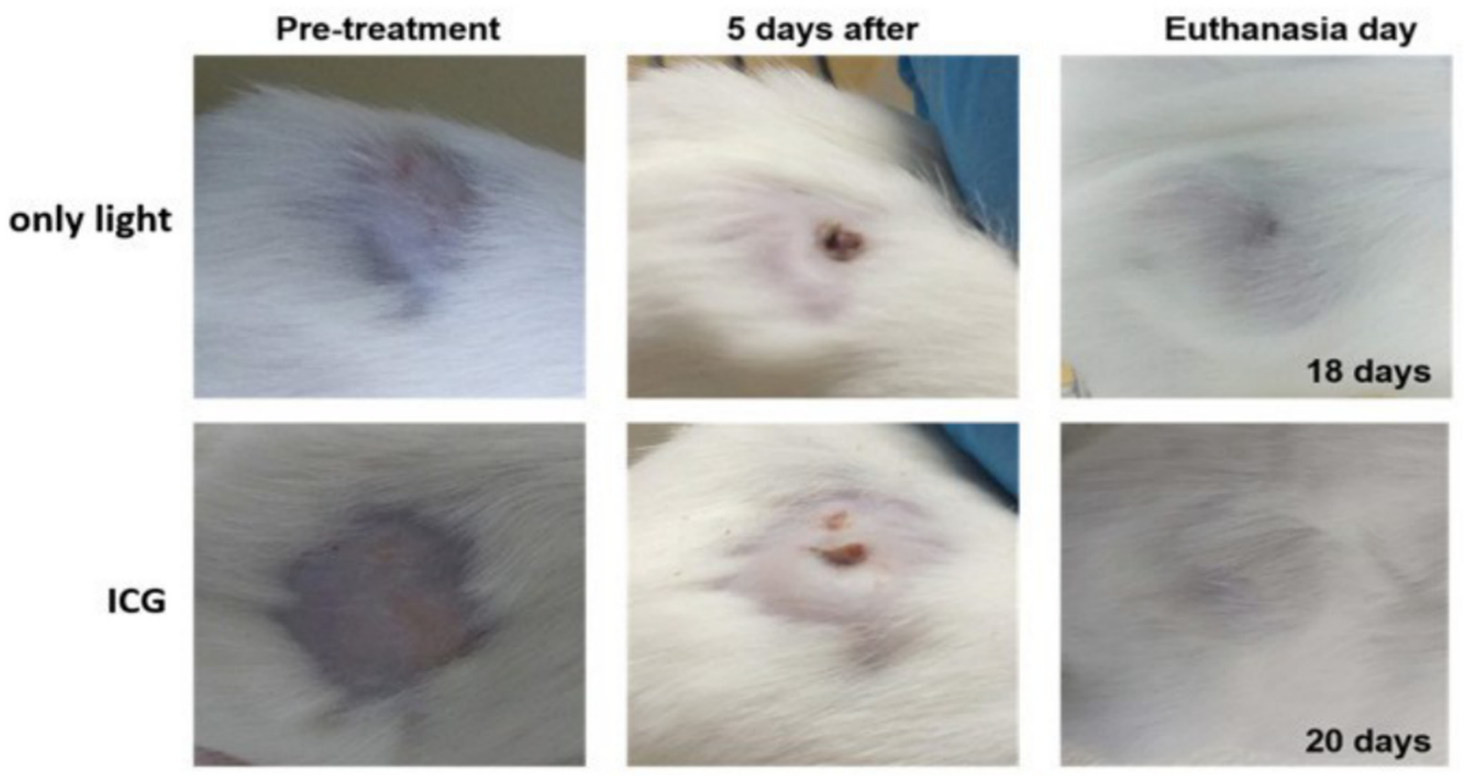

\section{GO+PEGFA+RhodB}
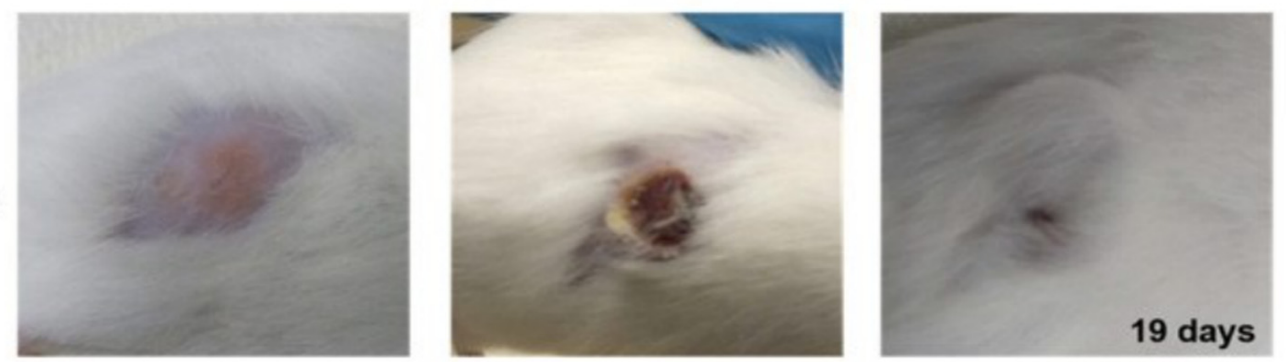

GO+PEGFA+ICG
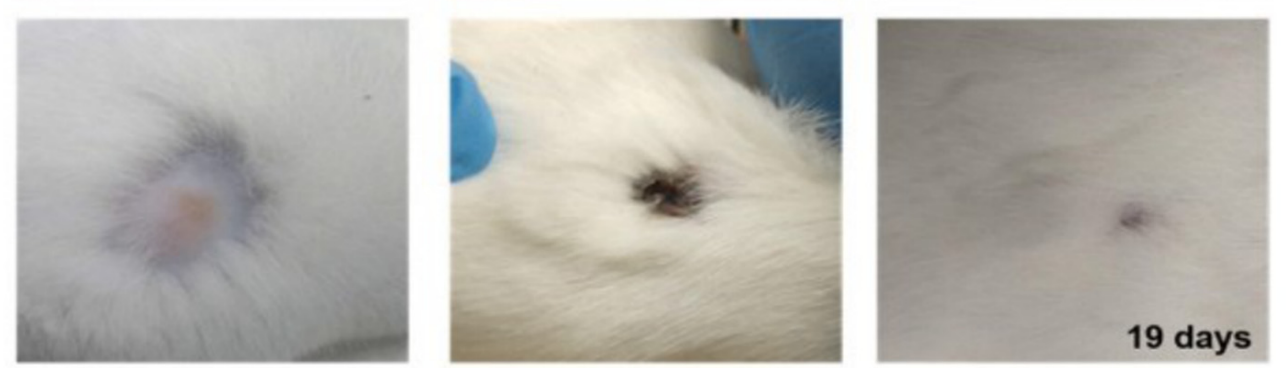

Figure 16. Representative mice images showing the sizes of tumors at pre-treatment day, 5 th day, and euthanasia day under $808 \mathrm{~nm}, 1.8 \mathrm{~W} / \mathrm{cm}^{2}$ for light, ICG, GO+PEGFA+RhodB, and GO+PEGFA+ICG mice groups. Reproduced from Ref. [72]. Copyright 2021 PMC.

\section{Toxicity and Immune Response of CBM}

The interaction of any nanoparticle with biological molecules depends on its physicochemical characteristics. Given the many advantages of CBM, it is also necessary to highlight the possible effects of toxicity. Composition, size, shape, charge, functionalization, and aggregation are some examples of these properties that must be studied and understood to avoid toxic effects. Nanomaterials, especially carbon-based, appear in different shapes and structures, such as particles, tubes, fibers, and films, and this variation directly affects their kinetics and delivery to the target cell (see Figure 17). Consequently, the route of transport in the environment is also affected [134]. 

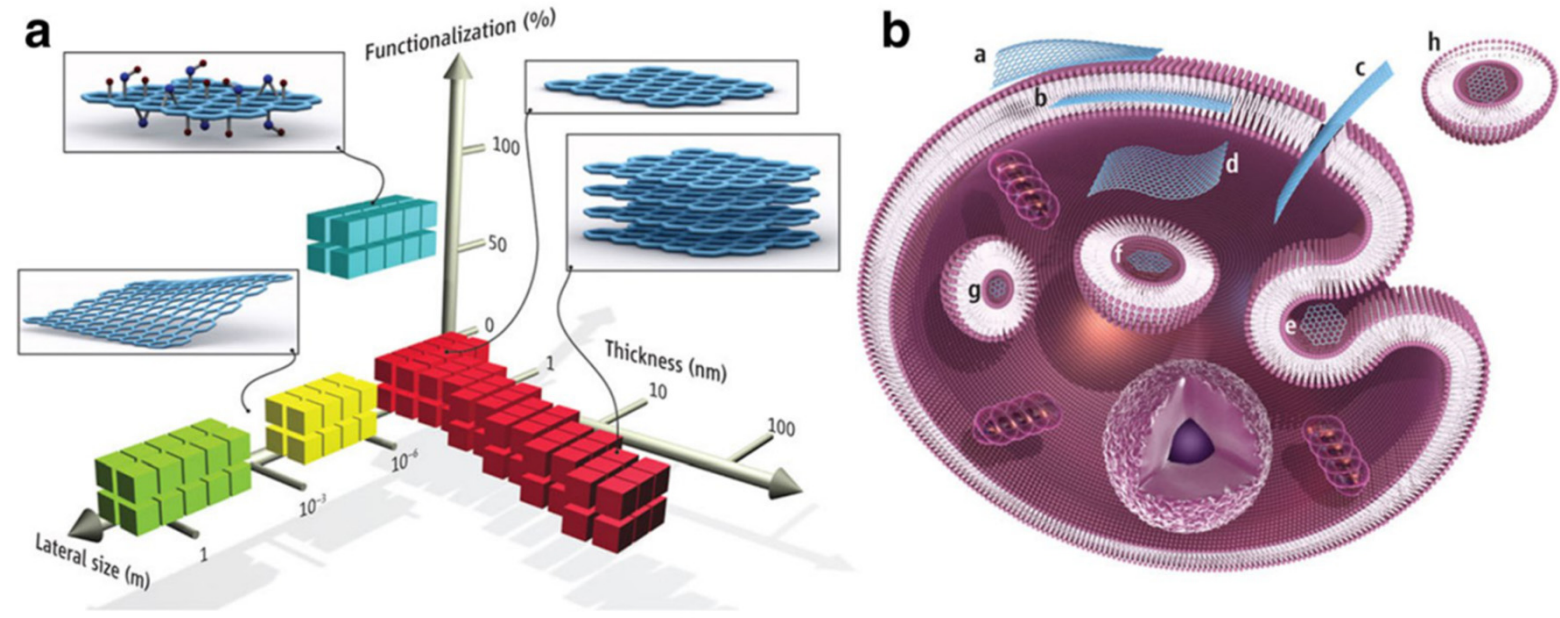

Figure 17. (a) CBM can be described by the dimensions and surface functionalization of the material (percentage of the carbon atoms in $\mathrm{sp}^{3}$ hybridization). Green squares represent epitaxially grown graphene; yellow, mechanically exfoliated graphene; red, chemically exfoliated graphene; blue, GO. (b) Possible interactions between CBM with cells (a) Adhesion onto the outer surface of the cell membrane. (b) Incorporation in between the monolayers of the plasma membrane lipid bilayer. (c) Translocation of the membrane. (d) Cytoplasmic internalization. (e) Clathrin-mediated endocytosis. (f) Endosomal or phagosomal internalization. (g) Lysosomal or other perinuclear compartment localization. (h) Exosomal localization. The biological outcomes from such interactions can be considered to be either adverse or beneficial, depending on the context of the particular biomedical application. Different CBM will have different preferential mechanisms of interaction with cells and tissues that largely await discovery. Reproduced from Ref. [135]. Copyright 2014 the American Association for the Advancement of Science.

ROS production is one of the essential mechanisms of toxicity of these nanomaterials and can lead to a chain of reactions ranging from inflammation and oxidative stress to protein denaturation and cell death [136]. This generation of ROS can reduce the membrane potential of mitochondria, causing damage to the cell and can react with fatty acids, causing lipid peroxidation. In the nucleus, CBM can also cause genotoxicity by interacting with DNA. These processes are the main factors related to toxicity and cell death caused by carbon-based nanomaterials [137].

The small size of nanomaterials enables them to cross biological barriers, including membranes, which can lead to cell damage (see Figure 18) [134]. Smaller CBM have shown greater oxidative capacity and have caused more oxidative damage to alveolar epithelial cells than the bigger ones [138]. Regarding graphene-based nanomaterials, GO, for example, due to their size, can cross cell membranes, which can damage them and promote cytoplasmic leakage with the generation of ROS [139]. Furthermore, when the surface area of nanoparticles is large, there is an increase in their binding capacity with other compounds on their surface, increasing their toxic effect in the biological environment. The bigger the surface area of CBM, the greater their oxidative potential, including the ability to damage DNA [140]. 


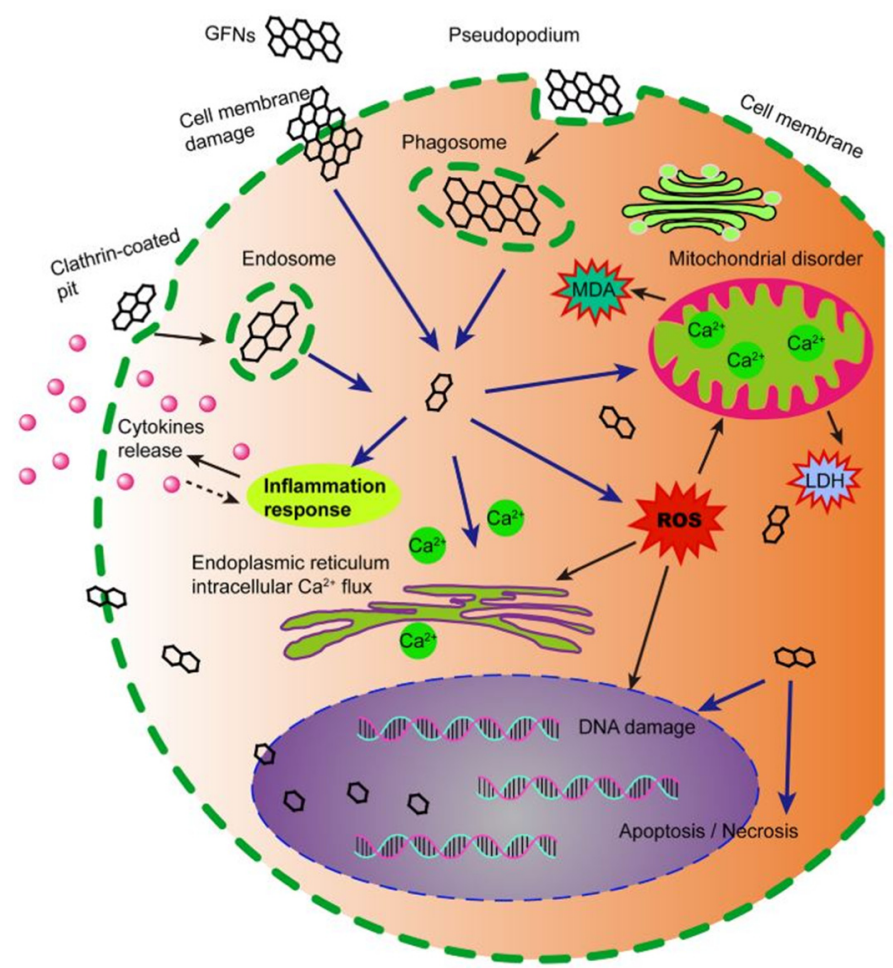

Figure 18. Schematic diagram showing the possible mechanisms of CBM cytotoxicity. CBM get into cells, which induces ROS generation, lactate dehydrogenase and malondialdehyde increase, and $\mathrm{Ca}^{2+}$ release. Subsequently, CBM cause kinds of cell injury, for instance, cell membrane damage, inflammation, DNA damage, mitochondrial disorders, apoptosis, or necrosis. Reproduced from Ref. [141]. Copyright 2016 Springer Nature.

Understanding the characteristics of CBM is essential to improving their biocompatibility. For example, carbon nanotubes are hydrophobic and can aggregate in the blood, and several strategies have been adopted to improve their delivery in the biological environment via the intravenous route [142]. Typically, in experiments for PDT and PTT, a concentration without dark toxicity is used. Thus, cell death must be due to the interaction of light with the compound (be it photosensitive or photothermal).

Different ligands should reduce cytotoxicity. In PEG-functionalized GO, no significant changes were observed in the Zebrafish model [143] compared to several already shown effects of GO without PEG. This functionalization improves its solubility and compatibility and has also reduced toxic effects in mice [144]. Intravenous administration of aminefunctionalized GO or only GO in mice proved the thrombogenic capacity of graphene, where functionalized graphene showed low toxicity [145]. Functionalization also changed the toxicity of single-wall carbon nanotubes, showing more biocompatibility for the presence of PEG since PEGylation alters its cytotoxic potential and has improved its excretion in animal tests [142].

For example, nano-GO modified with PEG ranging in concentration between 0 and $50 \mu \mathrm{g} / \mathrm{mL}$ maintain viability at more than $90 \%$ in the dark, which indicates low toxicity. However, when illuminated, cell viability drops to less than $60 \%$ for a light dose of $19.2 \mathrm{~J} / \mathrm{cm}^{2}$ [61]. Even when $\mathrm{r}-\mathrm{GO}$ is linked with other ligands besides PEG (such as molybdenum sulfide and manganese dioxide), varying the concentration from 25 to $200 \mu \mathrm{g} / \mathrm{mL}$, there is excellent viability in the dark, showing low toxicity [77]. When illuminating, however, viability reduces by about 70\%, as desired for PDT and PTT treatments.

Functionalization can also help increase specificity since only diseased cells will receive the nanoparticles, reducing toxicity in healthy tissues. Another possibility to improve CBM is their immobilization in a polymer matrix, preventing penetration into the cell and 
sealing its edges. However, these matrices must be very well studied concerning their biocompatibility for human application [139].

With the combined use of CBM with other drugs and specific ligands, it is possible to make complex molecules such as oxidized single-walled carbon nanotubes alloys with chemotherapy (docetaxel) and folic acid. Even when there is the presence of the chemotherapeutic agent in low concentrations, it can show low toxicity without illumination. At a concentration of $0.01 \mu \mathrm{M}$, this compound already shows a reduction in tumor cell viability of more than $20 \%$ in the dark. When illuminated, this reduction reaches more than $60 \%$ [146]. Therefore, understanding the toxicity and parameters involved in this process can generate more effective treatments, especially under lighting. When we analyzed the in vivo results of this study, there was no toxicity, showing that the inhibitory effect is only for the tumor and increases under irradiation.

It is necessary to understand the process of elimination and metabolism of CBM in the human body to be used in medicine. If they are not eliminated or accumulate in some vital organ, they can pose a health risk and, therefore, studies in this area are critical [142].

The cytotoxicity results of CBM are often contradictory. Not only because the physicalchemical characteristics can influence these results, but the synthesis process itself and the presence of metallic impurities can also influence them. Thus, it is still unclear what plays a central role in the immune response and the toxicity of these nanomaterials [147].

These results are found especially for graphene, whose structural properties directly influence its interaction with cells. Chemical oxidants and reducing agents used in graphene synthesis can result in organic contamination and metallic impurities, resulting in cell damage and increased toxicity. Carbon nanotubes are considered genotoxic, and this characteristic can be explained both by the fibrous property of these materials and the presence of impurities present in their composition [148]. The use of green synthesis can reduce their cytotoxicity and be a possibility in biomedical applications [139].

It should be noted that the prediction of in vivo toxicity from in vitro data does not necessarily reflect reality due to the different conditions of the cellular environment and the complex organism. However, understanding these processes can go a long way in controlling these toxic effects. In vivo studies can provide information about complex parameters such as metabolism and evaluation of the chronic effect, which can contrast with punctual in vitro results. The contradiction in the toxicity of the same compound may also result from these differences [134]. The poor dispersion of CBM in water also plays an essential role in the toxicity and reproducibility of both in vitro and in vivo assays [149].

CBM absorb over a broad region of the visible spectrum and can directly interfere in assays performed by fluorescence or absorption. Thus, the inconsistency concerning toxicity can still result from a technical inconsistency in the reading of toxicity tests with the use of CBM. Therefore, it is necessary to characterize these materials, especially regarding the reproducibility of toxicological tests. Ensuring the reproducibility of the technique itself ensures that better characterized and less toxic effects are found, which is significant as they are easily modified. Removing metallic impurities, adding binders on its surface, or increasing its dispersion are examples of processes with apparent effectiveness in producing less toxic materials [147].

Graphene and carbon nanotubes have different geometries. While the last one is shaped like a tube, as the name implies, the first one is formed by flat sheets. Thus, the interaction of these materials with the biological environment must happen through different mechanisms and, therefore, result in different responses, including specific toxicity and immunological effects [142]. Dose, interaction time, cell type, and animal lineage can influence the toxicity result [139].

The route of administration, such as oral, intraperitoneal, intravenous, or ocular, also interferes with the toxicity of CBM [150]. For example, studies have shown few toxic effects of graphene-based compounds on intraocular administration, with minimal effects on morphology and cell viability [151]. In comparison, studies have shown that graphene can induce chronic toxicity in mice from oral or systemic administration [139]. Pulmonary 
toxicity with multiple effects has also been reported, depending on the dose of graphene administered [144]. This also affects the toxicity of carbon nanotubes. Lung exposure leads to different effects, including genotoxic and intravenous injection that has resulted in the accumulation of carbon nanotubes in vital organs. However, these responses are mainly dependent on dose, functionalization, and physicochemical properties [152].

Graphene toxicity was shown to be dose-dependent, as it had significant effects at high doses in mice (such as inflammation and pulmonary edema), whereas it exhibited little or no effect at low and medium doses. Therefore, it is necessary to avoid general conclusions regarding these CBM. Understanding the biological interaction of the compounds (functionalized or not) can guarantee better results and may be the key to them being considered non-toxic [144].

Different compounds can interact with immune cells and trigger a response. As for toxicity, carbon-based compounds can act differently depending on their properties, such as size, shape, dispersion, and different functionalization [147].

Macrophage tests are the most used to study the immune response of these materials. Studies of cell uptake and viability and induction of an inflammatory response are some examples of these tests. Especially in macrophages, CBM have been exhibiting detrimental effects. However, the nanoparticle size may be definitive for this issue since, for example, short and long carbon nanotubes can show different effects. Another group of essential cells for the immune response is lymphocytes. CBM have been studied and both a positive and negative effect on modulating the cellular response of lymphocytes were determined, also showing the toxicity of these materials [147].

There are several in vitro toxicity studies with carbon nanotubes, especially in lung and skin cells and cells related to the immune system. Most have been showing decreases in cell proliferation, which can reduce the adhesion of carbon nanotubes, generating a series of reactions that will damage the membranes and cause cell death. Other studies have shown the potential for DNA damage and genetic alterations with carbon nanotubes [152].

In addition to the individual in vitro responses, in vivo tests allow studying the global immune response of compounds in the living organism from a systemic response. Studies with alveolar macrophages, inflammatory induction in the lungs, airway epithelial cells, and mast cells are some examples of what has been studied with CBM. Systemic activation of the immune response and the complement system are also possible with in vivo studies. Carbon nanotubes, for example, can activate this systemic response [147].

The use of high doses, the lack of standardization, exposure to professionals, and the effect on the environment are some examples of the origin of these problems. The development of regulations, whether in the production or disposal of these materials, is an essential step in reducing the adverse effects of nanomaterials and has been a concern of the global scientific community [134]. The influence of graphene on plantations has shown that it can induce adverse effects, including on plantation roots, being dose-dependent. The structure can also be a determining factor, as few layers did not significantly affect plant growth rates. Furthermore, high concentrations of graphene can affect microorganisms in the environment, including water, affecting plant growth and the general biome. Therefore, understanding toxicity must be a constant concern for those working with these compounds [144].

Although CBM have wide applications, before applying these materials for any research it is necessary to study and understand their intrinsic toxic effects, mainly because they often allow for structural modifications and subsequent reductions in toxicity, making them even more attractive for use in nanomedicine.

\section{Conclusions}

Based on the compilation presented in this review, it is evident that a wide range of carbon-based materials is being used within phototherapy and synergetic therapies to battle against cancer disease. Graphene oxide, reduced GO, graphene quantum dots, and carbon dots have been studied by several researchers showing excellent results for tumor 
destruction. Nevertheless, it is necessary to define standard guidelines for preparing and applying this type of material for therapeutic purposes. Researchers must employ in vivo and in vitro applications to humans. It is worth noting that the phototherapy field using carbon-based material is still in an emerging phase. Therefore, further exploration remains to be done until full high-quality implementation and commercialization can happen. A grand challenge is to develop a treatment with reduced dose-dependent toxicity to improve the care of cancer patients.

Author Contributions: Conceptualization M.P.R. and K.J.L.; writing, K.J.L., H.H.B., V.S.B. and M.P.R. All authors have read and agreed to the published version of the manuscript.

Funding: This research received no external funding.

Institutional Review Board Statement: Not applicable.

Informed Consent Statement: Not applicable.

Data Availability Statement: Not applicable.

Acknowledgments: Financial support from FAPESP (Fundação de Amparo à Pesquisa do Estado de São Paulo) grants 2013/07276-1 and 2016/14033-6. Escuela Politécnica Nacional Project PIIF-20-05.

Conflicts of Interest: The authors declare no conflict of interest.

\section{References}

1. Hohlfeld, B.F.; Gitter, B.; Flanagan, K.J.; Kingsbury, C.J.; Kulak, N.; Senge, M.O.; Wiehe, A. Exploring the relationship between structure and activity in BODIPYs designed for antimicrobial phototherapy. Org. Biomol. Chem. 2020, 18, 2416-2431. [CrossRef]

2. Zhou, S.; Wang, Z.; Wang, Y.; Feng, L. Near-Infrared Light-Triggered Synergistic Phototherapy for Antimicrobial Therapy. ACS Appl. Bio Mater. 2020, 3, 1730-1737. [CrossRef]

3. Gwynne, P.J.; Gallagher, M.P. Light as a broad-spectrum antimicrobial. Front. Microbiol. 2018, 9, 119. [CrossRef] [PubMed]

4. Zubair, R.; Hamzavi, I.H. Phototherapy for Vitiligo. Dermatol. Clin. 2020, 38, 55-62. [CrossRef] [PubMed]

5. Morita, A. Current developments in phototherapy for psoriasis. J. Dermatol. 2018, 45, 287-292. [CrossRef]

6. Kemény, L.; Varga, E.; Novak, Z. Advances in phototherapy for psoriasis and atopic dermatitis. Expert Rev. Clin. Immunol. 2019, 15, 1205-1214. [CrossRef]

7. Nikolaou, V.; Sachlas, A.; Papadavid, E.; Economidi, A.; Karambidou, K.; Marinos, L.; Stratigos, A.; Antoniou, C. Phototherapy as a first-line treatment for early-stage mycosis fungoides: The results of a large retrospective analysis. Photodermatol. Photoimmunol. Photomed. 2018, 34, 307-313. [CrossRef]

8. International Agency for Research on Cancer. Available online: https:/ / gco.iarc.fr/today/home (accessed on 30 October 2021).

9. Zhen, X.; Cheng, P.; Pu, K. Recent Advances in Cell Membrane-Camouflaged Nanoparticles for Cancer Phototherapy. Small 2019, 15, 1804105. [CrossRef] [PubMed]

10. Ma, Y.; Zhang, Y.; Li, X.; Zhao, Y.; Li, M.; Jiang, W.; Tang, X.; Dou, J.; Lu, L.; Wang, F.; et al. Near-infrared II phototherapy induces deep tissue immunogenic cell death and potentiates cancer immunotherapy. ACS Nano 2019, 13, 11967-11980. [CrossRef]

11. Xie, Z.; Fan, T.; An, J.; Choi, W.; Duo, Y.; Ge, Y.; Zhang, B.; Nie, G.; Xie, N.; Zheng, T.; et al. Emerging combination strategies with phototherapy in cancer nanomedicine. Chem. Soc. Rev. 2020, 49, 8065-8087. [CrossRef]

12. Sun, W.; Zhao, X.; Fan, J.; Du, J.; Peng, X. Boron Dipyrromethene Nano-Photosensitizers for Anticancer Phototherapies. Small 2019, 15, 1804927. [CrossRef]

13. Ng, C.W.; Li, J.; Pu, K. Recent Progresses in Phototherapy-Synergized Cancer Immunotherapy. Adv. Funct. Mater. 2018, 28, 1804688. [CrossRef]

14. Kim, M.M.; Darafsheh, A. Light Sources and Dosimetry Techniques for Photodynamic Therapy. Photochem. Photobiol. 2020, 96, 280-294. [CrossRef] [PubMed]

15. Zhang, S.; Li, Q.; Yang, N.; Shi, Y.; Ge, W.; Wang, W.; Huang, W.; Song, X.; Dong, X. Phase-Change Materials Based Nanoparticles for Controlled Hypoxia Modulation and Enhanced Phototherapy. Adv. Funct. Mater. 2019, 29, 1906805. [CrossRef]

16. Li, J.; Pu, K. Development of organic semiconducting materials for deep-tissue optical imaging, phototherapy and photoactivation. Chem. Soc. Rev. 2019, 48, 38-71. [CrossRef] [PubMed]

17. Wang, Y.; Jin, Y.; Chen, W.; Wang, J.; Chen, H.; Sun, L.; Li, X.; Ji, J.; Yu, Q.; Shen, L.; et al. Construction of nanomaterials with targeting phototherapy properties to inhibit resistant bacteria and biofilm infections. Chem. Eng. J. 2019, 358, 74-90. [CrossRef]

18. Lan, G.; Ni, K.; Lin, W. Nanoscale metal-organic frameworks for phototherapy of cancer. Coord. Chem. Rev. 2019, 379, 65-81. [CrossRef] [PubMed]

19. Jung, H.S.; Verwilst, P.; Sharma, A.; Shin, J.; Sessler, J.L.; Kim, J.S. Organic molecule-based photothermal agents: An expanding photothermal therapy universe. Chem. Soc. Rev. 2018, 47, 2280-2297. [CrossRef] 
20. Liu, Y.; Bhattarai, P.; Dai, Z.; Chen, X. Photothermal therapy and photoacoustic imaging: Via nanotheranostics in fighting cancer. Chem. Soc. Rev. 2019, 48, 2053-2108. [CrossRef]

21. Nafiujjaman, M.; Nurunnabi, M. Graphene and 2D Materials for Phototherapy; Elsevier Inc.: Amsterdam, The Netherlands, 2019; ISBN 9780128158890.

22. Del Rosal, B.; Jia, B.; Jaque, D. Beyond Phototherapy: Recent Advances in Multifunctional Fluorescent Nanoparticles for Light-Triggered Tumor Theranostics. Adv. Funct. Mater. 2018, 28, 1803733. [CrossRef]

23. Wiehe, A.; O'brien, J.M.; Senge, M.O. Trends and targets in antiviral phototherapy. Photochem. Photobiol. Sci. 2019, 18, $2565-2612$. [CrossRef]

24. Rajakumar, G.; Zhang, X.H.; Gomathi, T.; Wang, S.F.; Ansari, M.A.; Mydhili, G.; Nirmala, G.; Alzohairy, M.A.; Chung, I.M. Current use of carbon-based materials for biomedical applications-A prospective and review. Processes 2020, 8, 355. [CrossRef]

25. Lu, D.; Tao, R.; Wang, Z. Carbon-based materials for photodynamic therapy: A mini-review. Front. Chem. Sci. Eng. 2019, 13, 310-323. [CrossRef]

26. Zhu, H.; Ni, N.; Govindarajan, S.; Ding, X.; Leong, D.T. Phototherapy with layered materials derived quantum dots. Nanoscale 2020, 12, 43-57. [CrossRef]

27. Jiang, B.P.; Zhou, B.; Lin, Z.; Liang, H.; Shen, X.C. Recent Advances in Carbon Nanomaterials for Cancer Phototherapy Chem. A Eur. J. 2019, 25, 3993-4004. [CrossRef] [PubMed]

28. Abbas, A.; Mariana, L.T.; Phan, A.N. Biomass-waste derived graphene quantum dots and their applications. Carbon N. Y. 2018, 140, 77-99. [CrossRef]

29. Lian, Y.M.; Utetiwabo, W.; Zhou, Y.; Huang, Z.H.; Zhou, L.; Muhammad, F.; Chen, R.J.; Yang, W. From upcycled waste polyethylene plastic to graphene/mesoporous carbon for high-voltage supercapacitors. J. Colloid Interface Sci. 2019, 557, 55-64. [CrossRef]

30. Lee, X.J.; Hiew, B.Y.Z.; Lai, K.C.; Lee, L.Y.; Gan, S.; Thangalazhy-Gopakumar, S.; Rigby, S. Review on graphene and its derivatives: Synthesis methods and potential industrial implementation. J. Taiwan Inst. Chem. Eng. 2019, 98, 163-180. [CrossRef]

31. Lim, J.Y.; Mubarak, N.M.; Abdullah, E.C.; Nizamuddin, S.; Khalid, M. Inamuddin Recent trends in the synthesis of graphene and graphene oxide based nanomaterials for removal of heavy metals-A review. J. Ind. Eng. Chem. 2018, 66, 29-44. [CrossRef]

32. Kumar, A.; Sharma, K.; Dixit, A.R. A review of the mechanical and thermal properties of graphene and its hybrid polymer nanocomposites for structural applications. J. Mater. Sci. 2019, 54, 5992-6026. [CrossRef]

33. Mohan, V.B.; Lau, K.T.; Hui, D.; Bhattacharyya, D. Graphene-based materials and their composites: A review on production, applications and product limitations. Compos. Part B Eng. 2018, 142, 200-220. [CrossRef]

34. Wang, R.; Ren, X.G.; Yan, Z.; Jiang, L.J.; Sha, W.E.I.; Shan, G.C. Graphene based functional devices: A short review. Front. Phys. 2019, 14, 9-18. [CrossRef]

35. Zhu, Y.; Ji, H.; Cheng, H.M.; Ruoff, R.S. Mass production and industrial applications of graphene materials. Natl. Sci. Rev. 2018, 5, 90-101. [CrossRef]

36. Banerjee, A.N. Graphene and its derivatives as biomedical materials: Future prospects and challenges. Interface Focus 2018, 8 , 20170056. [CrossRef] [PubMed]

37. Seifi, T.; Reza Kamali, A. Antiviral performance of graphene-based materials with emphasis on COVID-19: A review. Med. Drug Discov. 2021, 11, 100099. [CrossRef] [PubMed]

38. Karahan, H.E.; Wiraja, C.; Xu, C.; Wei, J.; Wang, Y.; Wang, L.; Liu, F.; Chen, Y. Graphene Materials in Antimicrobial Nanomedicine: Current Status and Future Perspectives. Adv. Healthc. Mater. 2018, 7, 1701406. [CrossRef]

39. Sainz-Urruela, C.; Vera-López, S.; Andrés, M.P.S.; Díez-Pascual, A.M. Graphene-Based Sensors for the Detection of Bioactive Compounds: A review. Int. J. Mol. Sci. 2021, 22, 3316. [CrossRef]

40. Yang, K.; Feng, L.; Liu, Z. The advancing uses of nano-graphene in drug delivery. Expert Opin. Drug Deliv. 2015, 12, 601-612. [CrossRef]

41. Lin, J.; Huang, Y.; Huang, P. Graphene-Based Nanomaterials in Bioimaging. In Biomedical Applications of Functionalized Nanomaterials: Concepts, Development and Clinical Translation; Elsevier Inc.: Amsterdam, The Netherlands, 2018; pp. 247-287. ISBN 9780323508797.

42. Shin, S.R.; Li, Y.C.; Jang, H.L.; Khoshakhlagh, P.; Akbari, M.; Nasajpour, A.; Zhang, Y.S.; Tamayol, A.; Khademhosseini, A. Graphene-based materials for tissue engineering. Adv. Drug Deliv. Rev. 2016, 105, 255-274. [CrossRef] [PubMed]

43. Patel, S.C.; Lee, S.; Lalwani, G.; Suhrland, C.; Chowdhury, S.M.; Sitharaman, B. Graphene-based platforms for cancer therapeutics. Ther. Deliv. 2016, 7, 101-116. [CrossRef] [PubMed]

44. Yang, K.; Feng, L.; Zhuang, L. Stimuli responsive drug delivery systems based on nano-graphene for cancer therapy. Adv. Drug Deliv. Rev. 2016, 105, 228-241. [CrossRef]

45. Romero, M.P.; Marangoni, V.S.; de Faria, C.G.; Leite, I.S.; Maroneze, C.M.; Pereira-da-Silva, M.A.; Bagnato, V.S.; Inada, N.M. Graphene Oxide Mediated Broad-Spectrum Antibacterial Based on Bimodal Action of Photodynamic and Photothermal Effects. Front. Microbiol. 2020, 10, 2995. [CrossRef] [PubMed]

46. Chen, Y.W.; Su, Y.L.; Hu, S.H.; Chen, S.Y. Functionalized graphene nanocomposites for enhancing photothermal therapy in tumor treatment. Adv. Drug Deliv. Rev. 2016, 105, 190-204. [CrossRef] [PubMed]

47. Melios, C.; Giusca, C.E.; Panchal, V.; Kazakova, O. Water on graphene: Review of recent progress. 2D Mater. $2018,5,022001$. [CrossRef] 
48. Tadyszak, K.; Wychowaniec, J.K.; Litowczenko, J. Biomedical applications of graphene-based structures. Nanomaterials 2018, 8, 944. [CrossRef]

49. Dasari Shareena, T.P.; McShan, D.; Dasmahapatra, A.K.; Tchounwou, P.B. A Review on Graphene-Based Nanomaterials in Biomedical Applications and Risks in Environment and Health. Nano-Micro Lett. 2018, 10, 53. [CrossRef]

50. Suvarnaphaet, P.; Pechprasarn, S. Graphene-based materials for biosensors: A review. Sensors 2017, 17, 2161. [CrossRef]

51. Molaei, M.J. Carbon quantum dots and their biomedical and therapeutic applications: A review. RSC Adv. 2019, 9, 6460-6481. [CrossRef]

52. Yan, F.; Jiang, Y.; Sun, X.; Bai, Z.; Zhang, Y.; Zhou, X. Surface modification and chemical functionalization of carbon dots: A review. Microchim. Acta 2018, 185, 424. [CrossRef]

53. Tian, P.; Tang, L.; Teng, K.S.; Lau, S.P. Graphene quantum dots from chemistry to applications. Mater. Today Chem. 2018, 10, 221-258. [CrossRef]

54. Costa, M.C.F.; Marangoni, V.S.; Ng, P.R.; Nguyen, H.T.L.; Carvalho, A.; Castro Neto, A.H. Accelerated synthesis of graphene oxide from graphene. Nanomaterials 2021, 11, 551. [CrossRef]

55. Singh, D.P.; Herrera, C.E.; Singh, B.; Singh, S.; Singh, R.K.; Kumar, R. Graphene oxide: An efficient material and recent approach for biotechnological and biomedical applications. Mater. Sci. Eng. C 2018, 86, 173-197. [CrossRef]

56. Smith, A.T.; LaChance, A.M.; Zeng, S.; Liu, B.; Sun, L. Synthesis, properties, and applications of graphene oxide/reduced graphene oxide and their nanocomposites. Nano Mater. Sci. 2019, 1, 31-47. [CrossRef]

57. Justh, N.; Berke, B.; László, K.; Szilágyi, I.M. Thermal analysis of the improved Hummers' synthesis of graphene oxide. J. Therm. Anal. Calorim. 2018, 131, 2267-2272. [CrossRef]

58. Sharma, H.; Mondal, S. Functionalized graphene oxide for chemotherapeutic drug delivery and cancer treatment: A promising material in nanomedicine. Int. J. Mol. Sci. 2020, 21, 6280. [CrossRef]

59. Liu, L.; Ma, Q.; Cao, J.; Gao, Y.; Han, S.; Liang, Y.; Zhang, T.; Song, Y.; Sun, Y. Recent progress of graphene oxide-based multifunctional nanomaterials for cancer treatment. Cancer Nanotechnol. 2021, 12, 18. [CrossRef]

60. Hosseinzadeh, R.; Khorsandi, K.; Hosseinzadeh, G. Graphene oxide-methylene blue nanocomposite in photodynamic therapy of human breast cancer. J. Biomol. Struct. Dyn. 2018, 36, 2216-2223. [CrossRef]

61. Sun, X.; Zebibula, A.; Dong, X.; Zhang, G.; Zhang, D.; Qian, J.; He, S. Aggregation-Induced Emission Nanoparticles Encapsulated with PEGylated Nano Graphene Oxide and Their Applications in Two-Photon Fluorescence Bioimaging and Photodynamic Therapy in Vitro and in Vivo. ACS Appl. Mater. Interfaces 2018, 10, 25037-25046. [CrossRef] [PubMed]

62. Qin, X.; Zhang, H.; Wang, Z.; Jin, Y. Magnetic chitosan/graphene oxide composite loaded with novel photosensitizer for enhanced photodynamic therapy. RSC Adv. 2018, 8, 10376-10388. [CrossRef]

63. Huang, P.; Xu, C.; Lin, J.; Wang, C.; Wang, X.; Zhang, C.; Zhou, X.; Guo, S.; Cui, D. Folic Acid-conjugated Graphene Oxide loaded with Photosensitizers for Targeting Photodynamic Therapy. Theranostics 2012, 1, 240-250. [CrossRef] [PubMed]

64. Patil, T.V.; Patel, D.K.; Dutta, S.D.; Ganguly, K.; Lim, K.T. Graphene oxide-based stimuli-responsive platforms for biomedical applications. Molecules 2021, 26, 2797. [CrossRef]

65. Lim, J.H.; Kim, D.E.; Kim, E.J.; Ahrberg, C.D.; Chung, B.G. Functional Graphene Oxide-Based Nanosheets for Photothermal Therapy. Macromol. Res. 2018, 26, 557-565. [CrossRef]

66. Xie, M.; Zhang, F.; Peng, H.; Zhang, Y.; Li, Y.; Xu, Y.; Xie, J. Layer-by-layer modification of magnetic graphene oxide by chitosan and sodium alginate with enhanced dispersibility for targeted drug delivery and photothermal therapy. Colloids Surf. B Biointerfaces 2019, 176, 462-470. [CrossRef]

67. Huang, C.; Hu, X.; Hou, Z.; Ji, J.; Li, Z.; Luan, Y. Tailored graphene oxide-doxorubicin nanovehicles via near-infrared dyelactobionic acid conjugates for chemo-photothermal therapy. J. Colloid Interface Sci. 2019, 545, 172-183. [CrossRef]

68. Zhang, W.; Guo, Z.; Huang, D.; Liu, Z.; Guo, X.; Zhong, H. Synergistic effect of chemo-photothermal therapy using PEGylated graphene oxide. Biomaterials 2011, 32, 8555-8561. [CrossRef] [PubMed]

69. Tian, B.; Wang, C.; Zhang, S.; Feng, L.; Liu, Z. Photothermally enhanced photodynamic therapy delivered by nano-graphene oxide. ACS Nano 2011, 5, 7000-7009. [CrossRef] [PubMed]

70. Gulzar, A.; Xu, J.; Yang, D.; Xu, L.; He, F.; Gai, S.; Yang, P. Nano-graphene oxide-UCNP-Ce6 covalently constructed nanocomposites for NIR-mediated bioimaging and PTT/PDT combinatorial therapy. Dalt. Trans. 2018, 47, 3931-3939. [CrossRef]

71. Zhang, X.; Luo, L.; Li, L.; He, Y.; Cao, W.; Liu, H.; Niu, K.; Gao, D. Trimodal synergistic antitumor drug delivery system based on graphene oxide. Nanomed. Nanotechnol. Biol. Med. 2019, 15, 142-152. [CrossRef]

72. Romero, M.P.; Buzza, H.H.; Stringasci, M.D.; Estevão, B.M.; Silva, C.C.C.; Pereira-Da-silva, M.A.; Inada, N.M.; Bagnato, V.S. Graphene oxide theranostic effect: Conjugation of photothermal and photodynamic therapies based on an in vivo demonstration. Int. J. Nanomed. 2021, 16, 1601-1616. [CrossRef]

73. Coros, M.; Pogacean, F.; Turza, A.; Dan, M.; Berghian-Grosan, C.; Pana, I.O.; Pruneanu, S. Green synthesis, characterization and potential application of reduced graphene oxide. Phys. E Low-Dimens. Syst. Nanostruct. 2020, 119, 113971. [CrossRef]

74. Muzyka, R.; Drewniak, S.; Pustelny, T.; Chrubasik, M.; Gryglewicz, G. Characterization of graphite oxide and reduced graphene oxide obtained from different graphite precursors and oxidized by different methods using Raman spectroscopy. Materials 2018, 11, 1050. [CrossRef] [PubMed]

75. Tarcan, R.; Todor-Boer, O.; Petrovai, I.; Leordean, C.; Astilean, S.; Botiz, I. Reduced graphene oxide today. J. Mater. Chem. C 2020, 8, 1198-1224. [CrossRef] 
76. Dash, B.S.; Jose, G.; Lu, Y.J.; Chen, J.P. Functionalized reduced graphene oxide as a versatile tool for cancer therapy. Int. J. Mol. Sci. 2021, 22, 2989. [CrossRef]

77. Kapri, S.; Bhattacharyya, S. Molybdenum sulfide-reduced graphene oxide p-n heterojunction nanosheets with anchored oxygen generating manganese dioxide nanoparticles for enhanced photodynamic therapy. Chem. Sci. 2018, 9, 8982-8989. [CrossRef] [PubMed]

78. Vinothini, K.; Rajendran, N.K.; Rajan, M.; Ramu, A.; Marraiki, N.; Elgorban, A.M. A magnetic nanoparticle functionalized reduced graphene oxide-based drug carrier system for a chemo-photodynamic cancer therapy. New J. Chem. 2020, 44, 5265-5277. [CrossRef]

79. Jafarirad, S.; Hammami Torghabe, E.; Rasta, S.H.; Salehi, R. A novel non-invasive strategy for low-level laser-induced cancer therapy by using new $\mathrm{Ag} / \mathrm{ZnO}$ and $\mathrm{Nd} / \mathrm{ZnO}$ functionalized reduced graphene oxide nanocomposites. Artif. Cells Nanomed. Biotechnol. 2018, 46, 800-816. [CrossRef]

80. Lima-Sousa, R.; de Melo-Diogo, D.; Alves, C.G.; Costa, E.C.; Ferreira, P.; Louro, R.O.; Correia, I.J. Hyaluronic acid functionalized green reduced graphene oxide for targeted cancer photothermal therapy. Carbohydr. Polym. 2018, 200, 93-99. [CrossRef] [PubMed]

81. de Paula, R.F.O.; Rosa, I.A.; Gafanhão, I.F.M.; Fachi, J.L.; Melero, A.M.G.; Roque, A.O.; Boldrini, V.O.; Ferreira, L.A.B.; Irazusta, S.P.; Ceragioli, H.J.; et al. Reduced graphene oxide, but not carbon nanotubes, slows murine melanoma after thermal ablation using LED light in B16F10 lineage cells. Nanomed. Nanotechnol. Biol. Med. 2020, 28, 102231. [CrossRef]

82. Liu, W.; Zhang, X.; Zhou, L.; Shang, L.; Su, Z. Reduced graphene oxide (rGO) hybridized hydrogel as a near-infrared (NIR)/pH dual-responsive platform for combined chemo-photothermal therapy. J. Colloid Interface Sci. 2019, 536, 160-170. [CrossRef] [PubMed]

83. Zaharie-Butucel, D.; Potara, M.; Suarasan, S.; Licarete, E.; Astilean, S. Efficient combined near-infrared-triggered therapy: Phototherapy over chemotherapy in chitosan-reduced graphene oxide-IR820 dye-doxorubicin nanoplatforms. J. Colloid Interface Sci. 2019, 552, 218-229. [CrossRef]

84. Wang, L.; Wang, M.; Zhou, B.; Zhou, F.; Murray, C.; Towner, R.A.; Smith, N.; Saunders, D.; Xie, G.; Chen, W.R. PEGylated reduced-graphene oxide hybridized with Fe3O4 nanoparticles for cancer photothermal-immunotherapy. J. Mater. Chem. B 2019, 7 , 7406-7414. [CrossRef]

85. Wei, G.; Yan, M.; Ma, L.; Wang, C. Photothermal and photodynamic therapy reagents based on rGO-C6H4-COOH. RSC Adv. 2016, 6, 3748-3755. [CrossRef]

86. Zhang, D.Y.; Zheng, Y.; Tan, C.P.; Sun, J.H.; Zhang, W.; Ji, L.N.; Mao, Z.W. Graphene Oxide Decorated with Ru(II)-Polyethylene Glycol Complex for Lysosome-Targeted Imaging and Photodynamic/Photothermal Therapy. ACS Appl. Mater. Interfaces 2017, 9 6761-6771. [CrossRef]

87. Zhang, X.; Wei, C.; Li, Y.; Yu, D. Shining luminescent graphene quantum dots: Synthesis, physicochemical properties, and biomedical applications. TrAC Trends Anal. Chem. 2019, 116, 109-121. [CrossRef]

88. Wu, D.; Liu, Y.; Wang, Y.; Hu, L.; Ma, H.; Wang, G.; Wei, Q. Label-free Electrochemiluminescent Immunosensor for Detection of Prostate Specific Antigen based on Aminated Graphene Quantum Dots and Carboxyl Graphene Quantum Dots. Sci. Rep. 2016, 6, 20511. [CrossRef]

89. Tang, L.; Ji, R.; Li, X.; Bai, G.; Liu, C.P.; Hao, J.; Lin, J.; Jiang, H.; Teng, K.S.; Yang, Z.; et al. Deep ultraviolet to near-infrared emission and photoresponse in layered n-doped graphene quantum dots. ACS Nano 2014, 8, 6312-6320. [CrossRef] [PubMed]

90. Rakovich, A. Nanomaterials for biosensing and phototherapy applications. In Proceedings of the 2018 International Conference Laser Optics (ICLO), St. Petersburg, Russia, 4-8 June 2018. [CrossRef]

91. Jiang, C.; Zhao, H.; Xiao, H.; Wang, Y.; Liu, L.; Chen, H.; Shen, C.; Zhu, H.; Liu, Q. Recent advances in graphene-family nanomaterials for effective drug delivery and phototherapy. Expert Opin. Drug Deliv. 2020, 18, 119-138. [CrossRef] [PubMed]

92. Henna, T.K.; Pramod, K. Graphene quantum dots redefine nanobiomedicine. Mater. Sci. Eng. C 2020, 110, 110651. [CrossRef] [PubMed]

93. Ge, J.; Lan, M.; Zhou, B.; Liu, W.; Guo, L.; Wang, H.; Jia, Q.; Niu, G.; Huang, X.; Zhou, H.; et al. A graphene quantum dot photodynamic therapy agent with high singlet oxygen generation. Nat. Commun. 2014, 5, 4596. [CrossRef]

94. Tabish, T.A.; Scotton, C.J.; Ferguson, D.C.J.; Lin, L.; Van Der Veen, A.; Lowry, S.; Ali, M.; Jabeen, F.; Winyard, P.G.; Zhang, S. Biocompatibility and toxicity of graphene quantum dots for potential application in photodynamic therapy. Nanomedicine 2018, 13, 1923-1937. [CrossRef]

95. Campbell, E.; Hasan, M.T.; Gonzalez-Rodriguez, R.; Truly, T.; Lee, B.H.; Green, K.N.; Akkaraju, G.; Naumov, A.V. Graphene quantum dot formulation for cancer imaging and redox-based drug delivery. Nanomed. Nanotechnol. Biol. Med. 2021, 37, 102408. [CrossRef]

96. Chen, J.; Wu, W.; Zhang, F.; Zhang, J.; Liu, H.; Zheng, J.; Guo, S.; Zhang, J. Graphene quantum dots in photodynamic therapy. Nanoscale Adv. 2020, 2, 4961-4967. [CrossRef]

97. Kholikova, K.; Ilhoma, S.; Muhammed Sajjada, M.E.S.; Jerry, D.M.; Omer Sanc, A.O.E. Improved singlet oxygen generation and antimicrobial activity of sulphur-doped graphene quantum dots coupled with methylene blue for photodynamic therapy applications. Photodiagn. Photodyn. Ther. 2018, 24, 7-14. [CrossRef] [PubMed]

98. Fan, H.; Yu, X.; Wang, K.; Yin, Y.; Tang, Y.; Tang, Y.; Liang, X. Graphene quantum dots (GQDs)-based nanomaterials for improving photodynamic therapy in cancer treatment. Eur. J. Med. Chem. 2019, 182, 111620. [CrossRef] [PubMed] 
99. Liu, H.; Li, C.; Qian, Y.; Hu, L.; Fang, J.; Tong, W.; Nie, R.; Chen, Q.; Wang, H. Magnetic-induced graphene quantum dots for imaging-guided photothermal therapy in the second near-infrared window. Biomaterials 2020, 232, 119700. [CrossRef] [PubMed]

100. Yao, X.; Niu, X.; Ma, K.; Huang, P.; Grothe, J.; Kaskel, S.; Zhu, Y. Graphene Quantum Dots-Capped Magnetic Mesoporous Silica Nanoparticles as a Multifunctional Platform for Controlled Drug Delivery, Magnetic Hyperthermia, and Photothermal Therapy. Small 2017, 13, 1602225. [CrossRef]

101. Wang, H.; Mu, Q.; Wang, K.; Revia, R.A.; Yen, C.; Gu, X.; Tian, B.; Liu, J.; Zhang, M. Nitrogen and boron dual-doped graphene quantum dots for near-infrared second window imaging and photothermal therapy. Appl. Mater. Today 2019, 14, $108-117$. [CrossRef]

102. Li, S.; Zhou, S.; Li, Y.; Li, X.; Zhu, J.; Fan, L.; Yang, S. Exceptionally High Payload of the IR780 Iodide on Folic Acid-Functionalized Graphene Quantum Dots for Targeted Photothermal Therapy. ACS Appl. Mater. Interfaces 2017, 9, 22332-22341. [CrossRef]

103. Wang, C.; Chen, Y.; Xu, Z.; Chen, B.; Zhang, Y.; Yi, X.; Li, J. Fabrication and characterization of novel cRGD modified graphene quantum dots for chemo-photothermal combination therapy. Sens. Actuators B Chem. 2020, 309, 127732. [CrossRef]

104. Zheng, S.; Jin, Z.; Han, C.; Li, J.; Xu, H.; Park, S.; Park, J.O.; Choi, E.; Xu, K. Graphene quantum dots-decorated hollow copper sulfide nanoparticles for controlled intracellular drug release and enhanced photothermal-chemotherapy. J. Mater. Sci. 2020, 55, 1184-1197. [CrossRef]

105. Thakur, M.; Kumawat, M.K.; Srivastava, R. Multifunctional graphene quantum dots for combined photothermal and photodynamic therapy coupled with cancer cell tracking applications. RSC Adv. 2017, 7, 5251-5261. [CrossRef]

106. Liu, J.; Li, R.; Yang, B. Carbon Dots: A New Type of Carbon-Based Nanomaterial with Wide Applications. ACS Cent. Sci. 2020, 6 , 2179-2195. [CrossRef]

107. Feng, J.; Chen, S.; Yu, Y.L.; Wang, J.H. Red-emission hydrophobic porphyrin structure carbon dots linked with transferrin for cell imaging. Talanta 2020, 217, 121014. [CrossRef]

108. Jiang, K.; Wang, Y.; Gao, X.; Cai, C.; Lin, H. Facile, Quick, and Gram-Scale Synthesis of Ultralong-Lifetime Room-TemperaturePhosphorescent Carbon Dots by Microwave Irradiation. Angew. Chem. Int. Ed. 2018, 57, 6216-6220. [CrossRef]

109. Liu, M.L.; Chen, B.B.; Li, C.M.; Huang, C.Z. Carbon dots: Synthesis, formation mechanism, fluorescence origin and sensing applications. Green Chem. 2019, 21, 449-471. [CrossRef]

110. Zhang, Z.; Yi, G.; Li, P.; Zhang, X.; Fan, H.; Zhang, Y.; Wang, X.; Zhang, C. A minireview on doped carbon dots for photocatalytic and electrocatalytic applications. Nanoscale 2020, 12, 13899-13906. [CrossRef]

111. Jia, Q.; Zhao, Z.; Liang, K.; Nan, F.; Li, Y.; Wang, J.; Ge, J.; Wang, P. Recent advances and prospects of carbon dots in cancer nanotheranostics. Mater. Chem. Front. 2020, 4, 449-471. [CrossRef]

112. Boakye-Yiadom, K.O.; Kesse, S.; Opoku-Damoah, Y.; Filli, M.S.; Aquib, M.; Joelle, M.M.B.; Farooq, M.A.; Mavlyanova, R.; Raza, F.; Bavi, R.; et al. Carbon dots: Applications in bioimaging and theranostics. Int. J. Pharm. 2019, 564, 308-317. [CrossRef]

113. Li, Y.; Zheng, X.; Zhang, X.; Liu, S.; Pei, Q.; Zheng, M.; Xie, Z. Porphyrin-Based Carbon Dots for Photodynamic Therapy of Hepatoma. Adv. Healthc. Mater. 2017, 6, 1600924. [CrossRef] [PubMed]

114. Huang, P.; Lin, J.; Wang, X.; Wang, Z.; Zhang, C.; He, M.; Wang, K.; Chen, F.; Li, Z.; Shen, G.; et al. Light-Triggered Theranostics Based on Photosensitizer-Conjugated Carbon Dots for Simultaneous Enhanced-Fluorescence Imaging and Photodynamic Therapy. Adv. Mater. 2012, 24, 5104-5110. [CrossRef]

115. Qin, X.; Liu, J.; Zhang, Q.; Chen, W.; Zhong, X.; He, J. Synthesis of Yellow-Fluorescent Carbon Nano-dots by Microplasma for Imaging and Photocatalytic Inactivation of Cancer Cells. Nanoscale Res. Lett. 2021, 16, 14. [CrossRef]

116. Nocito, G.; Calabrese, G.; Forte, S.; Petralia, S.; Puglisi, C.; Campolo, M.; Esposito, E.; Conoci, S. Carbon dots as promising tools for cancer diagnosis and therapy. Cancers 2021, 13, 1991. [CrossRef] [PubMed]

117. Meena, R.; Singh, R.; Marappan, G.; Kushwaha, G.; Gupta, N.; Meena, R.; Gupta, J.P.; Agarwal, R.R.; Fahmi, N.; Kushwaha, O.S. Fluorescent carbon dots driven from ayurvedic medicinal plants for cancer cell imaging and phototherapy. Heliyon 2019, 5 e02483. [CrossRef]

118. Sun, S.; Zhang, L.; Jiang, K.; Wu, A.; Lin, H. Toward High-Efficient Red Emissive Carbon Dots: Facile Preparation, Unique Properties, and Applications as Multifunctional Theranostic Agents. Chem. Mater. 2016, 28, 8659-8668. [CrossRef]

119. Geng, B.; Yang, D.; Pan, D.; Wang, L.; Zheng, F.; Shen, W.; Zhang, C.; Li, X. NIR-responsive carbon dots for efficient photothermal cancer therapy at low power densities. Carbon N. Y. 2018, 134, 153-162. [CrossRef]

120. Zhang, M.; Wang, W.; Cui, Y.; Chu, X.; Sun, B.; Zhou, N.; Shen, J. Magnetofluorescent Fe3O4/carbon quantum dots coated singlewalled carbon nanotubes as dual-modal targeted imaging and chemo/photodynamic/photothermal triple-modal therapeutic agents. Chem. Eng. J. 2018, 338, 526-538. [CrossRef]

121. Li, Y.; Bai, G.; Zeng, S.; Hao, J. Theranostic Carbon Dots with Innovative NIR-II Emission for in Vivo Renal-Excreted Optical Imaging and Photothermal Therapy. ACS Appl. Mater. Interfaces 2019, 11, 4737-4744. [CrossRef] [PubMed]

122. Jia, Q.; Zheng, X.; Ge, J.; Liu, W.; Ren, H.; Chen, S.; Wen, Y.; Zhang, H.; Wu, J.; Wang, P. Synthesis of carbon dots from Hypocrella bambusae for bimodel fluorescence/photoacoustic imaging-guided synergistic photodynamic/photothermal therapy of cancer. J. Colloid Interface Sci. 2018, 526, 302-311. [CrossRef]

123. Zhao, S.; Wu, S.; Jia, Q.; Huang, L.; Lan, M.; Wang, P.; Zhang, W. Lysosome-targetable carbon dots for highly efficient photother$\mathrm{mal} /$ photodynamic synergistic cancer therapy and photoacoustic/two-photon excited fluorescence imaging. Chem. Eng. J. 2020, 388, 124212. [CrossRef] 
124. Lan, M.; Guo, L.; Zhao, S.; Zhang, Z.; Jia, Q.; Yan, L.; Xia, J.; Zhang, H.; Wang, P.; Zhang, W. Carbon Dots as Multifunctional Phototheranostic Agents for Photoacoustic/Fluorescence Imaging and Photothermal/Photodynamic Synergistic Cancer Therapy. Adv. Ther. 2018, 1, 1800077. [CrossRef]

125. Sun, S.; Chen, J.; Jiang, K.; Tang, Z.; Wang, Y.; Li, Z.; Liu, C.; Wu, A.; Lin, H. Ce6-Modified Carbon Dots for Multimodal-ImagingGuided and Single-NIR-Laser-Triggered Photothermal/Photodynamic Synergistic Cancer Therapy by Reduced Irradiation Power. ACS Appl. Mater. Interfaces 2019, 11, 5791-5803. [CrossRef]

126. Guo, X.L.; Ding, Z.Y.; Deng, S.M.; Wen, C.C.; Shen, X.C.; Jiang, B.P.; Liang, H. A novel strategy of transition-metal doping to engineer absorption of carbon dots for near-infrared photothermal/photodynamic therapies. Carbon N. Y. 2018, 134, 519-530. [CrossRef]

127. Yang, W.; Wei, B.; Yang, Z.; Sheng, L. Facile synthesis of novel carbon-dots/hemin nanoplatforms for synergistic photo-thermal and photo-dynamic therapies. J. Inorg. Biochem. 2019, 193, 166-172. [CrossRef]

128. Ge, J.; Jia, Q.; Liu, W.; Lan, M.; Zhou, B.; Guo, L.; Zhou, H.; Zhang, H.; Wang, Y.; Gu, Y.; et al. Carbon Dots with Intrinsic Theranostic Properties for Bioimaging, Red-Light-Triggered Photodynamic/Photothermal Simultaneous Therapy In Vitro and In Vivo. Adv. Healthc. Mater. 2016, 5, 665-675. [CrossRef]

129. Shi, J.; Ma, R.; Wang, L.; Zhang, J.; Liu, R.; Li, L.; Liu, Y.; Hou, L.; Yu, X.; Gao, J.; et al. The application of hyaluronic acidderivatized carbon nanotubes in hematoporphyrin monomethyl ether-based photodynamic therapy for in vivo and in vitro cancer treatment. Int. J. Nanomed. 2013, 8, 2361-2373. [CrossRef]

130. Moore, C.M.; Pendse, D.; Emberton, M. Photodynamic therapy for prostate cancer-a review of current status and future promise. Nat. Clin. Pract. Urol. 2009, 6, 18-30. [CrossRef] [PubMed]

131. Dias, L.D.; Buzzá, H.H.; Stringasci, M.D.; Bagnato, V.S. Recent Advances in Combined Photothermal and Photodynamic Therapies against Cancer Using Carbon Nanomaterial Platforms for In Vivo Studies. Photochem 2021, 1, 434-450. [CrossRef]

132. Xie, L.; Wang, G.; Zhou, H.; Zhang, F.; Guo, Z.; Liu, C.; Zhang, X.; Zhu, L. Functional long circulating single walled carbon nanotubes for fluorescent/photoacoustic imaging-guided enhanced phototherapy. Biomaterials 2016, 103, 219-228. [CrossRef]

133. Hua, X.W.; Bao, Y.W.; Wu, F.G. Fluorescent Carbon Quantum Dots with Intrinsic Nucleolus-Targeting Capability for Nucleolus Imaging and Enhanced Cytosolic and Nuclear Drug Delivery. ACS Appl. Mater. Interfaces 2018, 10, 10664-10677. [CrossRef]

134. Madannejad, R.; Shoaie, N.; Jahanpeyma, F.; Darvishi, M.H.; Azimzadeh, M.; Javadi, H. Toxicity of carbon-based nanomaterials: Reviewing recent reports in medical and biological systems. Chem. Biol. Interact. 2019, 307, 206-222. [CrossRef] [PubMed]

135. Kostarelos, K.; Novoselov, K.S. Exploring the interface of graphene and biology. Science 2014, 344, 261-263. [CrossRef]

136. Fard, J.K.; Jafari, S.; Eghbal, M.A. A Review of Molecular Mechanisms Involved in Toxicity of Nanoparticles. Tabriz Univ. Med. Sci. 2015, 5, 447-454. [CrossRef]

137. Pelin, M.; Fusco, L.; Martín, C.; Sosa, S.; Frontiñán-Rubio, J.; González-Domínguez, J.M.; Durán-Prado, M.; Vázquez, E.; Prato, M.; Tubaro, A. Graphene and graphene oxide induce ROS production in human HaCaT skin keratinocytes: The role of xanthine oxidase and NADH dehydrogenase. Nanoscale 2018, 10, 11820-11830. [CrossRef]

138. Koike, E.; Kobayashi, T. Chemical and biological oxidative effects of carbon black nanoparticles. Chemosphere 2006, 65, 946-951. [CrossRef]

139. Liao, C.; Li, Y.; Tjong, S.C. Graphene nanomaterials: Synthesis, biocompatibility, and cytotoxicity. Int. J. Mol. Sci. 2018, 19, 3564. [CrossRef] [PubMed]

140. Chuang, H.C.; Chen, L.C.; Lei, Y.C.; Wu, K.Y.; Feng, P.H.; Cheng, T.J. Surface area as a dose metric for carbon black nanoparticles: A study of oxidative stress, DNA single-strand breakage and inflammation in rats. Atmos. Environ. 2015, 106, 329-334. [CrossRef]

141. Ou, L.; Song, B.; Liang, H.; Liu, J.; Feng, X.; Deng, B.; Sun, T.; Shao, L. Toxicity of graphene-family nanoparticles: A general review of the origins and mechanisms. Part. Fibre Toxicol. 2016, 13, 1-24. [CrossRef] [PubMed]

142. Zhang, Y.; Petibone, D.; Xu, Y.; Mahmood, M.; Karmakar, A.; Casciano, D.; Ali, S.; Biris, A.S. Toxicity and efficacy of carbon nanotubes and graphene: The utility of carbon-based nanoparticles in nanomedicine. Drug Metab. Rev. 2014, 46, 232-246. [CrossRef]

143. Liu, C.W.; Xiong, F.; Jia, H.Z.; Wang, X.L.; Cheng, H.; Sun, Y.H.; Zhang, X.Z.; Zhuo, R.X.; Feng, J. Graphene-based anticancer nanosystem and its biosafety evaluation using a zebrafish model. Biomacromolecules 2013, 14, 358-366. [CrossRef] [PubMed]

144. Seabra, A.B.; Paula, A.J.; De Lima, R.; Alves, O.L.; Durán, N. Nanotoxicity of graphene and graphene oxide. Chem. Res. Toxicol. 2014, 27, 159-168. [CrossRef]

145. Singh, S.K.; Singh, M.K.; Kulkarni, P.P.; Sonkar, V.K.; Grácio, J.J.A.; Dash, D. Amine-Modified Graphene: Thrombo-Protective Safer Alternative to Graphene Oxide for Biomedical Applications. ACS Nano 2012, 6, 2731-2740. [CrossRef]

146. Zhu, X.; Huang, S.; Huang, H.; Zhang, Y.; Xie, Y.; Hou, L.; Zhang, H.; Shi, J.; Zhang, Z. In vitro and in vivo anti-cancer effects of targeting and photothermal sensitive solid lipid nanoparticles. J. Drug Target. 2014, 22, 822-828. [CrossRef] [PubMed]

147. Yuan, X.; Zhang, X.; Sun, L.; Wei, Y.; Wei, X. Cellular Toxicity and Immunological Effects of Carbon-based Nanomaterials. Part. Fibre Toxicol. 2019, 16, 18. [CrossRef] [PubMed]

148. Lindberg, H.K.; Falck, G.C.M.; Suhonen, S.; Vippola, M.; Vanhala, E.; Catalán, J.; Savolainen, K.; Norppa, H. Genotoxicity of nanomaterials: DNA damage and micronuclei induced by carbon nanotubes and graphite nanofibres in human bronchial epithelial cells in vitro. Toxicol. Lett. 2009, 186, 166-173. [CrossRef] [PubMed]

149. Hurt, R.H.; Monthioux, M.; Kane, A. Toxicology of carbon nanomaterials: Status, trends, and perspectives on the special issue. Carbon N. Y. 2006, 44, 1028-1033. [CrossRef] 
150. Yang, K.; Gong, H.; Shi, X.; Wan, J.; Zhang, Y.; Liu, Z. In vivo biodistribution and toxicology of functionalized nano-graphene oxide in mice after oral and intraperitoneal administration. Biomaterials 2013, 34, 2787-2795. [CrossRef]

151. Yan, L.; Wang, Y.; Xu, X.; Zeng, C.; Hou, J.; Lin, M.; Xu, J.; Sun, F.; Huang, X.; Dai, L.; et al. Can graphene oxide cause damage to eyesight? Chem. Res. Toxicol. 2012, 25, 1265-1270. [CrossRef]

152. Heister, E.; Brunner, E.W.; Dieckmann, G.R.; Jurewicz, I.; Dalton, A.B. Are carbon nanotubes a natural solution? applications in biology and medicine. ACS Appl. Mater. Interfaces 2013, 5, 1870-1891. [CrossRef] 